\title{
BMJ Open Prevalence and burden of chronic kidney disease among the general population and high-risk groups in Africa: a systematic review
}

\author{
Samar Abd ElHafeez, ${ }^{1}$ Davide Bolignano, ${ }^{2}$ Graziella D'Arrigo, ${ }^{2}$ Evangelia Dounousi, ${ }^{3}$ \\ Giovanni Tripepi, ${ }^{2}$ Carmine Zoccali $^{2}$
}

To cite: Abd ElHafeez S, Bolignano D, D'Arrigo G, et al. Prevalence and burden of chronic kidney disease among the general population and high-risk groups in Africa: a systematic review. BMJ Open 2018;8:e015069. doi:10.1136/ bmjopen-2016-015069

- Prepublication history and additional material for this paper are available online. To view these files, please visit the journal online (http://dx.doi. org/10.1136/bmjopen-2016015069).

Received 15 November 2016 Revised 25 August 2017 Accepted 1 September 2017

CrossMark

${ }^{1}$ Department of Epidemiology, High Institute of Public Health - Alexandria University, Alexandria, Egypt

${ }^{2}$ Clinical Epidemiology of Renal Diseases and Hypertension, Reggio Cal Unit, CNR/IFC, Reggio Calabria, Italy

${ }^{3}$ Department of Nephrology, School of Health Sciences University of loannina, Ioannina, Greece

Correspondence to Dr Carmine Zoccali; carmine.zoccali@tin.it

\section{ABSTRACT}

Objectives While increasing attention is paid to the rising prevalence of chronic diseases in Africa, there is little focus on chronic kidney disease (CKD). This systematic review assesses CKD burden among the general population and high-risk groups on the entire African continent.

Design, setting and participants We searched Medline and PubMed databases for articles published between 1 January 1995 and 7 April 2017 by sensitive search strategies focusing on CKD surveys at the community level and high-risk groups. In total, 7918 references were evaluated, of which 7766 articles were excluded because they did not meet the inclusion criteria. Thus, 152 studies were included in the final analysis.

Outcome measurement The prevalence of CKD in each study group was expressed as a range and pooled prevalence rate of CKD was calculated as a point estimate and $95 \% \mathrm{Cl}$. No meta-analysis was done. Data were presented for different populations.

Results In the community-level studies, based on available medium-quality and high-quality studies, the prevalence of CKD ranged from $2 \%$ to $41 \%$ (pooled prevalence: $10.1 \% ; 95 \% \mathrm{Cl} 9.8 \%$ to $10.5 \%$ ). The prevalence of CKD in the high-risk groups ranged from $1 \%$ to $46 \%$ (pooled prevalence: $5.6 \%$; $95 \% \mathrm{Cl} 5.4 \%$ to $5.8 \%$ ) in patients with HIV (based on available medium-quality and high-quality studies), $11 \%-90 \%$ (pooled prevalence: $24.7 \%$; $95 \% \mathrm{Cl} 23.6 \%$ to $25.7 \%$ ) in patients with diabetes (based on all available studies which are of low quality except four of medium quality) and $13 \%-51 \%$ (pooled prevalence: $34.5 \%$; $95 \% \mathrm{Cl} 34.04 \%$ to $36 \%$ ) in patients with hypertension (based on all available studies which are of low quality except two of medium quality).

Conclusion In Africa, CKD is a public health problem, mainly attributed to high-risk conditions as hypertension and diabetes. The poor data quality restricts the validity of the findings and draws the attention to the importance of designing future robust studies.

\section{INTRODUCTION}

Chronic kidney disease (CKD) is an emerging global public health problem. ${ }^{1}$ The disease is a component of a new epidemic of chronic
Strengths and limitations of this study

- This systematic review assessed the chronic kidney disease (CKD) burden among the general population and high-risk groups on the entire African continent based on studies that covered all of Africa from 1 January 1995 until 7 April 2017.

- The quality of the included articles was assessed based on standard criteria dealing with clinical trials, diagnostic studies and observational studies. The articles were assessed based on the population sampling and precision, sampling technique, response rate and exclusion rate.

- No meta-analysis was conducted in this review due to the huge discrepancy in the definition used to identify CKD, the methods of creatinine measurement, urine protein assessment and in the quality of the reporting.

- There is paucity of information about CKD prevalence in age and gender groups, which affects the accuracy of the pooled prevalence estimated from each group.

- The prevalence of CKD reported in this review should be interpreted with caution due to the low quality of the majoirty of studies in Africa, the bias introduced from the heterogeneity between studies, analytical and methodological issues, sample size, and study population selection.

conditions that replaced malnutrition and infection as leading causes of mortality during the 20th century. ${ }^{2}$ Age-standardised death rates due to CKD have increased during the last 23 years. CKD has shifted from the 36th cause of death in 1990 to the 19th cause in 2013. ${ }^{3}$ The worldwide increase in CKD and kidney failure-necessitating renal replacement therapy-and the high rate of cardiovascular mortality and morbidity attributable to CKD are poised to reach epidemic proportions over the next decade. CKD complications represent a considerable burden on global healthcare resources and only a small 
number of countries have sufficiently robust economies to meet the challenge posed by this disease. Socioeconomic differences in health exist and individuals of lower socioeconomic status (SES) have a higher risk for mortality and morbidity compared with those of higher SES. ${ }^{4}$ A change in the global approach to CKD from the treatment of end stage renal disease (ESRD) to intensive primary and secondary prevention is therefore considered an absolute public health priority. ${ }^{5}$

Africa is the second largest continent in the world, with a population of over 1 billion; 961.5 million people live in sub-Saharan Africa and 195 million in Northern Africa. ${ }^{6}$ Africa now faces the dual challenge of infectious illnesses and chronic diseases. Africa's chronic disease burden is secondary to various factors, including increased life expectancy, changing lifestyle practices, poverty, urbanisation and globalisation. ${ }^{7}$ The World Health Assembly advocated the Global Action Plan for the Prevention and Control of Non-Communicable Diseases 2013-2020. One of its targets is to reduce premature mortality from chronic diseases by $25 \%$ in 2025 . These actions have the potential to make a significant impact on the burden of CKD. ${ }^{8}$ Unfortunately, CKD problem remains underestimated on the entire continent due to lack of epidemiological information from different African countries. There exists only a single systematic review conducted in sub-Saharan Africa, which concluded that CKD is a prevalent and potentially escalating disease across sub-Saharan Africa, with both communicable and non-communicable risk factors. ${ }^{9}$ Strategies aimed at managing CKD epidemics in Africa critically depend on a reliable assessment of the burden of the problem and the establishment of affordable early detection programmes. Previous studies reported the prevalence of CKD among the general population or the specific prevalence of this condition in diseases that are recognised as drivers of renal damage (eg, diabetes mellitus). These estimates have varied across studies due to differences in the methods of glomerular filtration rate (GFR) measurement, background risk (general population vs high-risk groups) or demographic characteristics (eg, age, gender). ${ }^{10}$

With this background in mind, this review aimed to increase the systematic information on the burden of CKD in the general population and high-risk groups of the entire African continent and provide an estimate of the prevalence of CKD in different regions of Africa.

\section{MATERIALS AND METHODS \\ Data source and search strategy}

We followed the Preferred Reporting Items for Systematic Reviews and Meta-Analyses guidelines. ${ }^{11}$ A systematic literature search was performed in the PubMed and Ovid Medline databases by two authors (DB and SA) to identify articles reporting epidemiology data on CKD in the adult population in any geographical area of the African continent. This employed focused, highly sensitive search strategies (online supplementary table 1). The search covered the time frame from 1 January 1995 to 7 April 2017. Papers without language and study design restrictions were located and screened. References from relevant studies were screened for supplementary articles.

\section{Study selection and data extraction}

Titles and abstracts were screened independently by two authors (SA and GD), who discarded studies that were not relevant to the topic. Case reports, reviews, editorials, letters and studies focusing on African-Americans not living on the African continent, conducted entirely among children, or dealing with acute kidney injury or kidney transplantation were excluded. Two authors (SA and ED) independently assessed the retrieved abstracts and the full texts of these studies to determine eligibility according to the inclusion criteria. Disagreements were resolved through discussion and consensus, or through consultation with a third reviewer (DB), who solved these differences based on study judgements. Furthermore, screening of reference lists of all of the retrieved studies was conducted to check for relevant articles, and a supplementary scan of the reference lists of the systematic reviews was performed to identify any additional studies. Data were extracted from full-text articles and registered using a specifically designed form. These data included study design, geographical area, sample size, the definition of CKD used, prevalence of CKD, age, gender, GFR measurement, type of creatinine assay, proteinuria, the method of outcome assessment, and associated comorbidities such as diabetes mellitus and hypertension. Data extraction was performed by one reviewer (SA) and independently verified by another reviewer $(\mathrm{DB})$.

\section{Data extraction and analysis}

Studies were categorised according to the reference population as follows: (1) studies dealing with the general population and (2) studies focusing on particular diseases such as diabetes, hypertension, lupus and HIV, or settings, for example, hospital-based surveys and occupational studies.

Information on the assessment of kidney function was collected, including the equation adopted for GFR estimation (Cockroft-Gault (CG), Modification of Diet in Renal Disease (MDRD), Chronic Kidney Disease-Epidemiology Collaboration (CKD-EPI)), the type of creatinine assay (Jaffe, standardised or unknown), and the type of proteinuria or albuminuria assay used (semiquantitative assessment by urinary strips or quantitative in urine samples or 24-hour collection). When the study included two or three GFR equations, we defined the CKD prevalence based on the CKD-EPI equation whenever this information was provided. Otherwise, we considered the MDRD equation and lastly the CG equation. In the case of ethnicity correction, ${ }^{12-14}$ we included the equation that corrected for ethnicity. Information on the definition of CKD used in each study was also included (either the internationally accepted definition as Kidney Disease 
Outcome Quality Initiative (KDOQI), or other ways of defining CKD).

\section{Quality assessment}

Two independent authors (SA and DB) appraised each article independently and assessed its quality based on standard criteria described into details in previous methodology reviews dealing with clinical trials,${ }^{15}$ diagnostic studies $^{16}$ and observational studies. ${ }^{17}$ The articles were assessed based on the subject sampling and precision, sampling technique, response rate, method of assessment of kidney function and exclusion rate.

\section{Statistical analyses}

The principal demographic and clinical data for each study were summarised as the mean and SD or as absolute number and percentage, as appropriate. The age range in each study was also recorded. The range of the CKD prevalence for each study group was reported. The pooled prevalence rate of CKD was expressed as a point estimate and $95 \%$ CI. The prevalence from each study was weighed by the sample size, then the pooled prevalence was categorised by the African region. The interrater agreement for inclusion and quality assessment was determined using Cohen's kappa $(\kappa)$ coefficient. ${ }^{18}$ The percentage of the different causes of CKD was weighed by the sample size of each study done among patients with CKD. Then we simply summed the number of patients for each aetiological factor and divided it by the total sample size from the whole included studies. No meta-analysis was conducted in this study. Data were appropriately presented for different populations (general population and patients with CKD). Patients' data were stratified by the type of underlying condition, that is, hypertension, diabetes mellitus, HIV or systemic lupus erythematosus. All calculations were conducted using SPSS for Windows V.21.

\section{RESULTS}

\section{Search results}

The flow diagram of the selection process is depicted in figure 1. In total, 7897 potentially relevant references were initially retrieved. Twenty-one additional citations were found through a personal search. By screening titles and abstracts, a total of 7534 citations were excluded because of search overlap, dealing with the wrong population (African-American, acute kidney injury (AKI), cancer or post-transplant patients) or not providing actual data on CKD. Review articles, case reports, editorials or letters were also excluded. Among the 384 studies selected for full-text examination, 232 were excluded because they dealt with a population different from that specifically targeted in this systematic review, such as paediatric populations (122 studies), transplant patients $(\mathrm{n}=44)$ or others
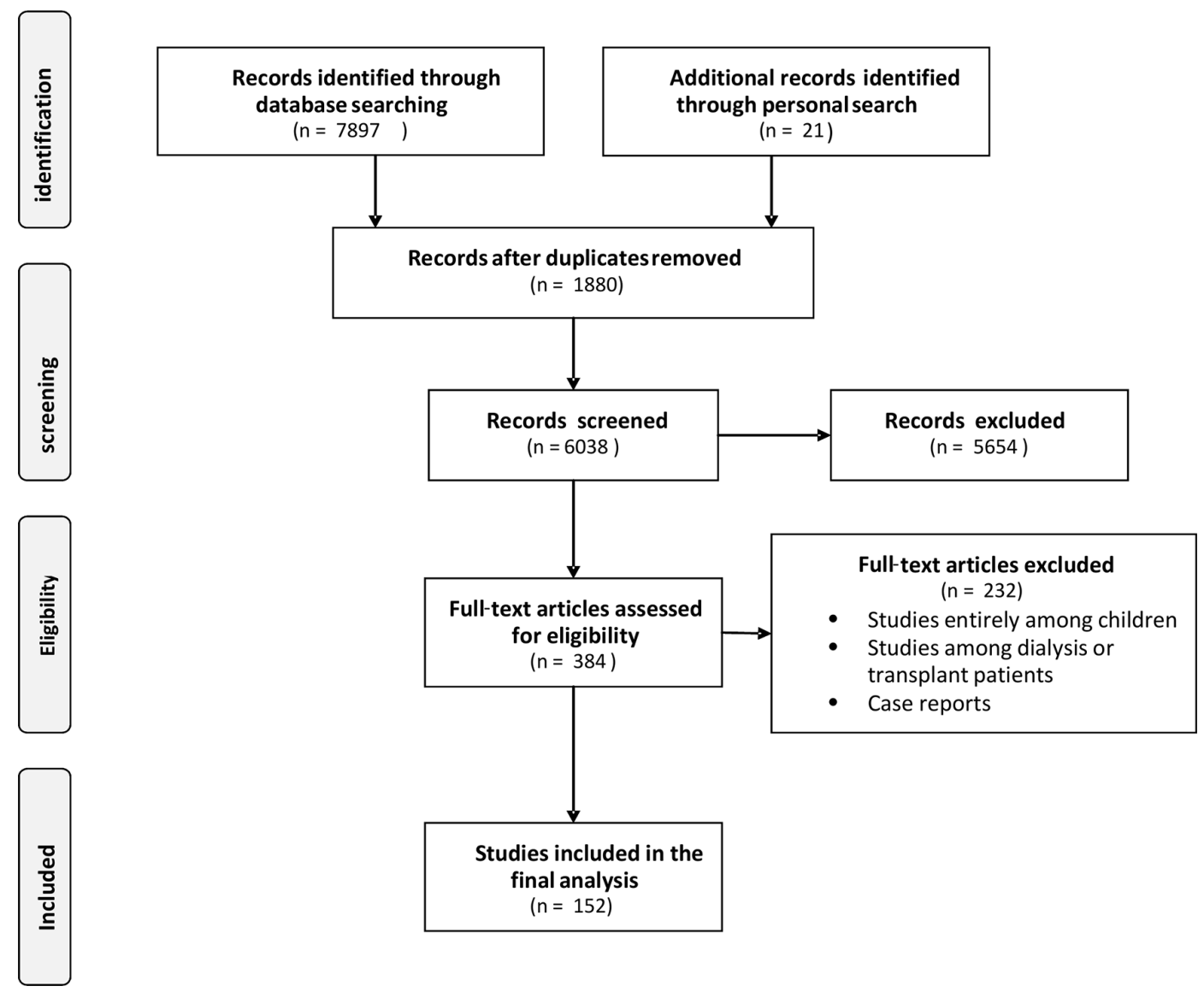

Figure 1 Flow diagram of the study selection. 


\begin{tabular}{|c|c|c|}
\hline Study population & Studies (n) & Study characteristics \\
\hline General population & 29 & $n=30169$, age ranging from 12 to 95 years; $48 \%$ male \\
\hline Patients with diabetes & 18 & $\mathrm{n}=9082$, age ranging from 14 to 90 years; $43 \%$ male \\
\hline Patients with hypertension & 9 & $n=4123$, age ranging from 19 to 90 years; $43 \%$ male \\
\hline Patients with HIV & 42 & $\mathrm{n}=67432$, age ranging from 13 to 74 years; $36 \%$ male \\
\hline Occupational group & 2 & $\begin{array}{l}n=153 \text {, age ranging from } 22 \text { to } 59 \text { years; one study only enrolled } \\
\text { women and the other principally enrolled men }\end{array}$ \\
\hline Family practice patients & 7 & $\mathrm{n}=3250$, age ranging from 20 to 74 years; $44 \%$ male \\
\hline Patients with lupus & 1 & $n=43$, age ranging from 16 to 55 years; $7 \%$ male \\
\hline Rheumatoid arthritis & 1 & $\mathrm{n}=233$, age ranging from 40 to 70 years; $17.2 \%$ male \\
\hline Sickle cell anaemia & 1 & $\mathrm{n}=194$, age ranging from 12 to 40 years; $43.3 \%$ male \\
\hline Patients with chronic kidney disease & 42 & $\mathrm{n}=34236$, age ranging from 12 to 90 years; $58 \%$ male \\
\hline
\end{tabular}

( $\mathrm{n}=46)$ (eg, Africans living in non-African countries), or because only narrative data were provided $(n=20)$. A total of 152 articles were therefore reviewed in detail and included in the analysis. The main characteristics of these studies are summarised in table 1 . The inter-rater agreement for inclusion wa-s $\kappa=0.90$ and for the quality assessment was $\kappa=0.85$.

\section{Study characteristics}

Among the 152 studies reviewed, 29 were general population studies (table 2). One hundred and twenty-three studies focused on selected groups, of which 42 included patients with HIV (table 3), 18 studied patients with diabetes (table 4), 9 included hypertensive subjects (table 5) and 12 were conducted in other populations (table 6), including one study in patients with lupus, ${ }^{19}$ one study in patients with rheumatoid arthritis, ${ }^{20}$ one study among patients with sickle cell anaemia, ${ }^{21}$ two in specific occupational settings (silica exposure ${ }^{22}$ and exposure to the nephrotoxic hair-dye, paraphenylenediamine ${ }^{23}$ ) and seven studies in family practice or hospital-based $^{27-30}$ surveys. Forty-two studies were conducted among patients with CKD (online supplementary table 2)..$^{31-72}$

The studies that were included covered all regions of Africa. The highest number of the studies came from the Western macro-area $(n=54)$, followed by the Eastern macro-area $(n=32)$ and Southern macro-area $(n=25)$. Twenty studies were retrieved from Northern Africa, and eight studies from each of the Central macro-area and the Central-Western macro-area. Three studies were conducted in both the Eastern and Southern regions and two studies in the sub-Saharan region.

\section{Assessment of kidney function impairment}

Urinary markers for kidney disease were assessed in 78 $(71 \%)$ among 110 studies conducted in the general population, high-risk groups, occupational or hospital-based studies. Proteinuria was assessed by a semiquantitative method (urinary strips) in 28 studies. $^{21} 24$ 2629 73-96 Twenty studies used dipstick with confirmation by quantitative methods, nine of which used dipsticks to identify proteinuria/albuminuria with confirmation by 24-hour proteinuria, ${ }^{25}$ 97-104 whereas 11 studies used dipstick with confirmation by the protein-to-creatinine ratio or albumin-to-creatinine ratio. ${ }^{105-115}$ Quantitative methods for the assessment of proteinuria/albuminuria (24-hour proteinuria or albuminuria, Protein to Creatine Ratio (PCR), immunoassay or Albumin to Creatinine Ratio (ACR) were applied in 29 studies. $19272830116-140$ In one study, the method of proteinuria assessment was not mentioned. ${ }^{141}$

Serum creatinine was measured in 95 studies $(86 \%)$. The Jaffe assay was used in 30 studies, ${ }^{29} 30768082838690$ $9597102105111113124126130131136142-152$ whereas the isotope dilution mass spectrometry (IDMS)-calibrated method was used in 15 studies. $^{12} 142126115117$ 132-134 141 153-157 In nine studies, both the Jaffe assay and the calibrated serum creatinine were used. ${ }^{132025919899106112158}$ The remaining 41 studies provided no information on the method of creatinine measurement. $19242728787981848587-89939496100$ 101104109114116 118-122 125127135 137-139 159-167 With respect to the formula used for estimating GFR, the MDRD equation was used in 30 studies 24-26 28 29 94-97 105106111113116117 121122126130133134136141146149153154158159164 and the CG equation was used in 18. ${ }^{19} 768186-8893100102114119124138143$ 145150162167 The other 14 studies used both the CG and the MDRD equations, ${ }^{78-80} 83-859899101144147152161163$ whereas 15 studies estimated GFR by the CG, MDRD and the CKD-EPI methods. ${ }^{12-14} 20829091109112115139142155156160$ Six studies used MDRD and CKD-EPI ${ }^{131} 132137148151157$ and two studies used CKD-EPI. ${ }^{21} 166$ In other two studies the formula was not mentioned. ${ }^{30135}$

\section{Definition of CKD}

Thirty-one studies defined the presence of CKD as an estimated glomerular filtration rate (eGFR) below $60 \mathrm{~mL} /$ $\mathrm{min} / 1.73 \mathrm{~m}^{2}$, 12142080 93-96111 117119139146 148-159 161-164166167 with chronicity confirmed by repeated testing in four other studies. ${ }^{142-145}$ Moreover, 28 studies reported CKD prevalence based on eGFR below $60 \mathrm{~mL} / \mathrm{min} / 1.73 \mathrm{~m}^{2}$ and/ or the presence of proteinuria or albuminuria. ${ }^{2124} 267678$ 

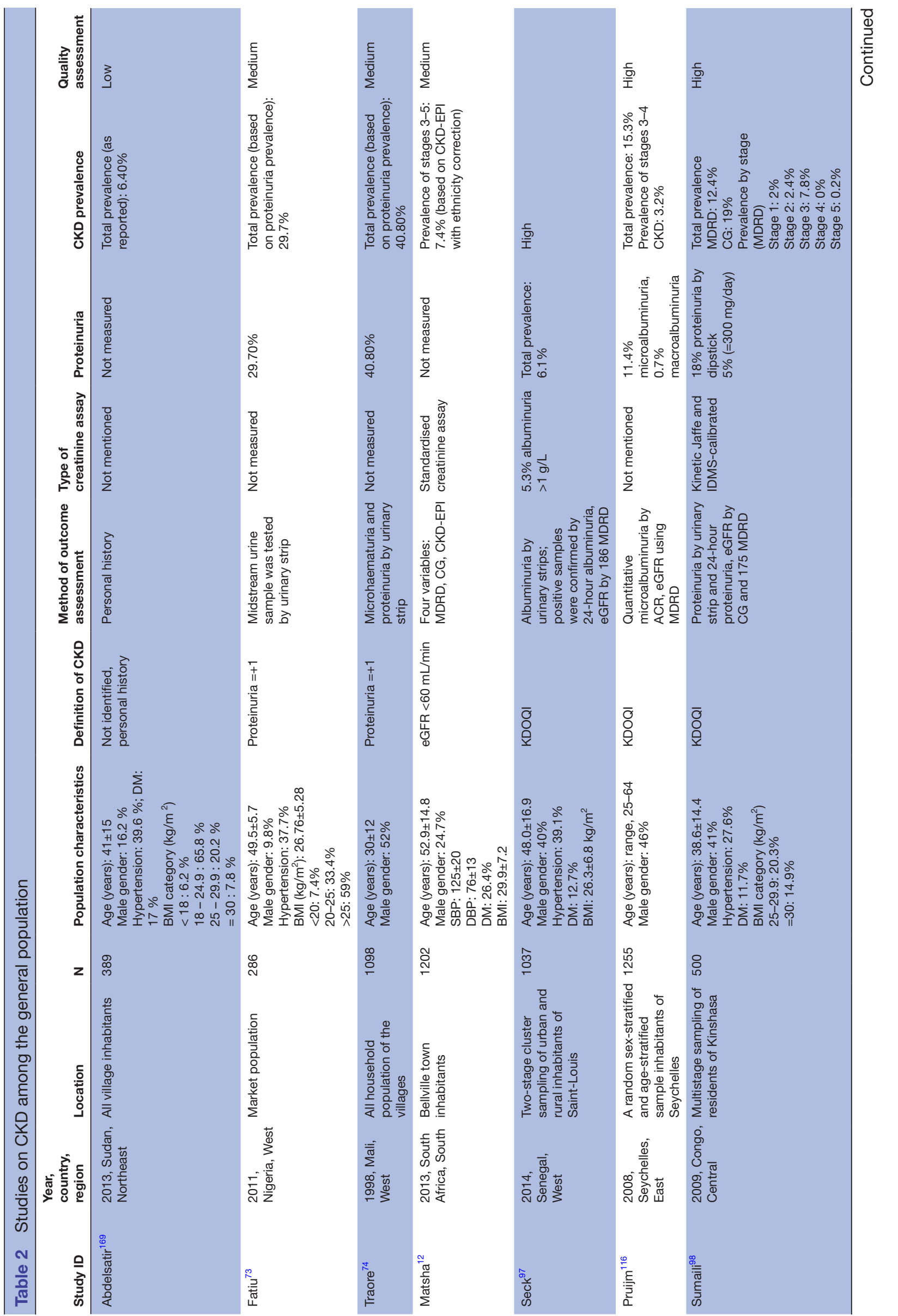

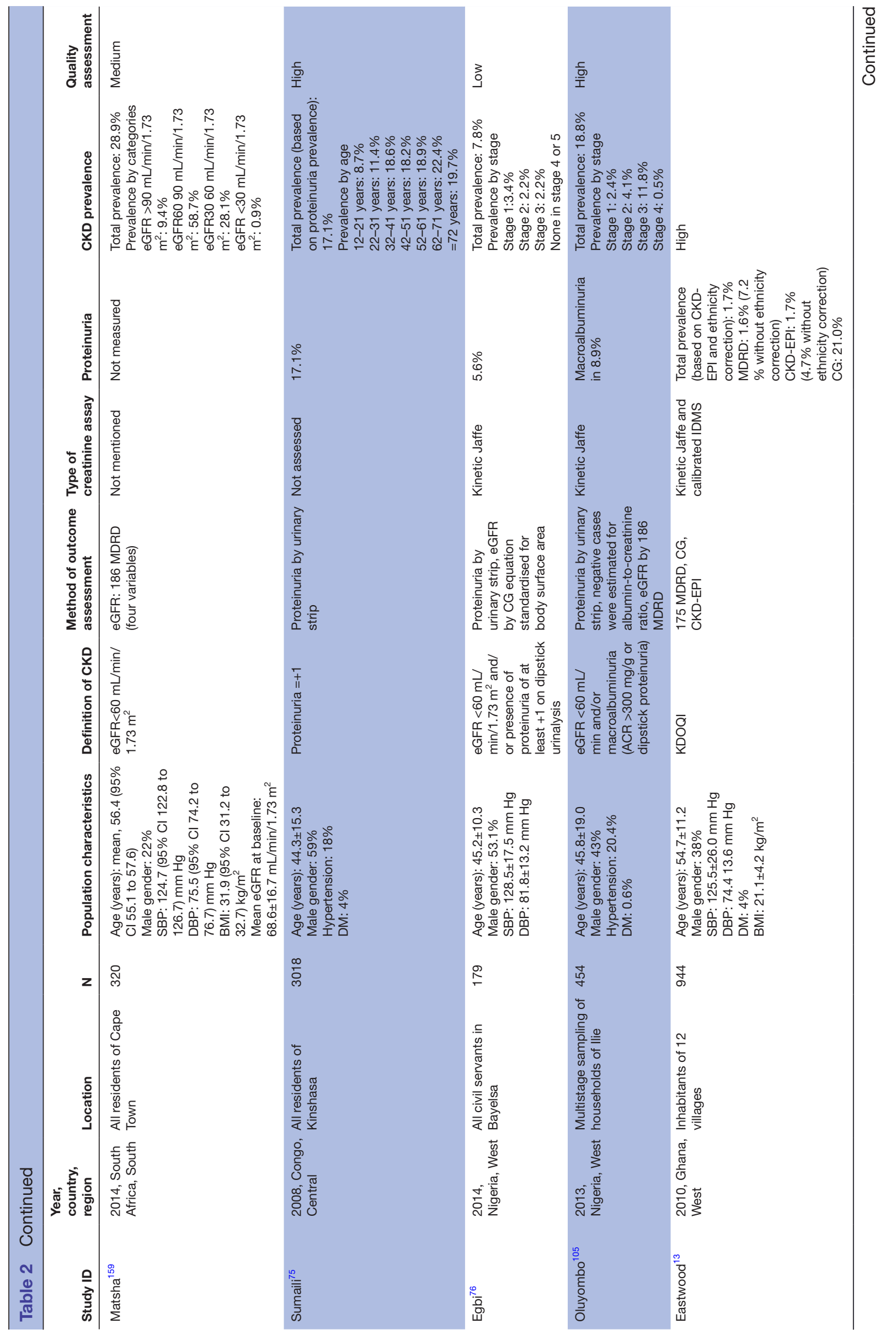


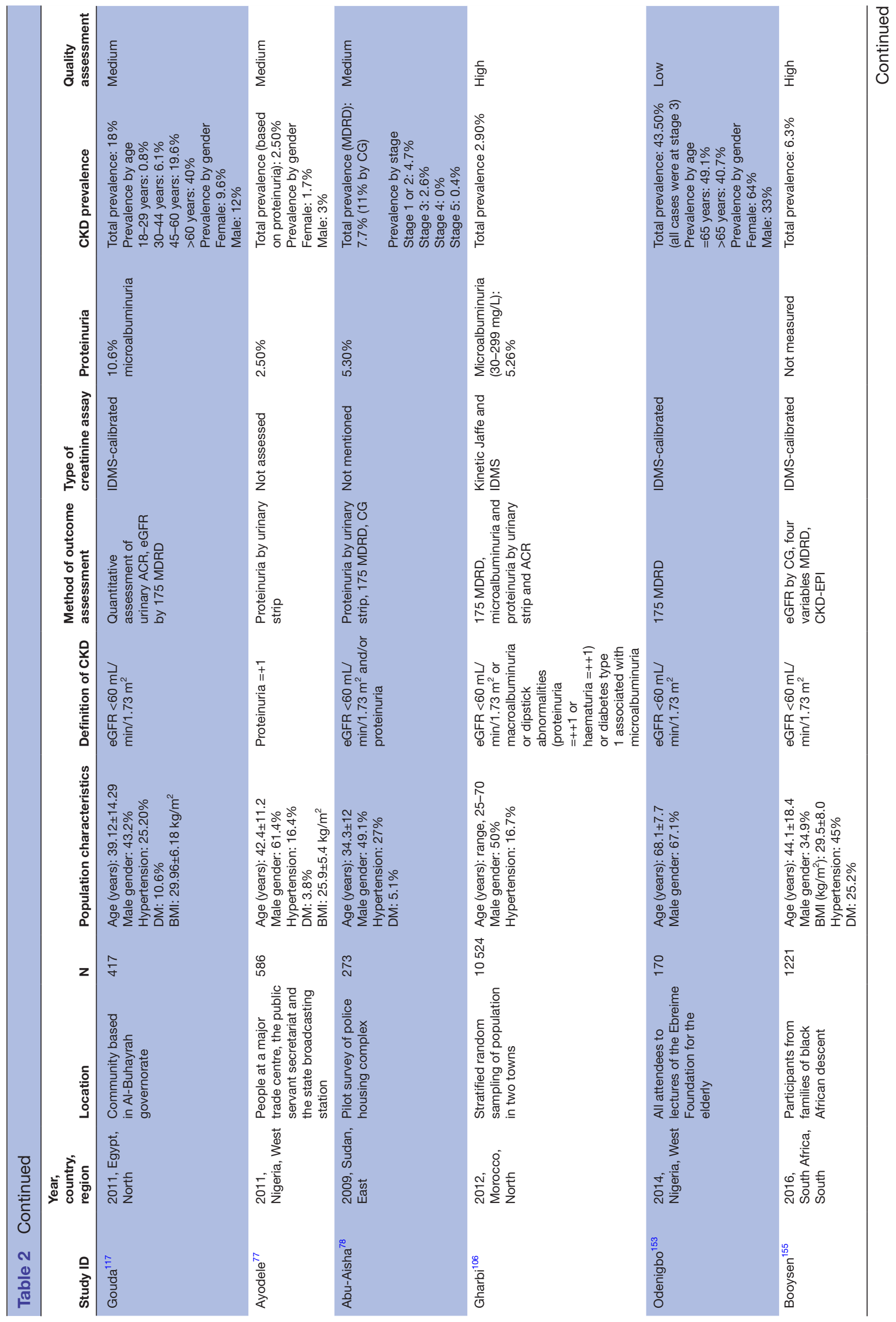




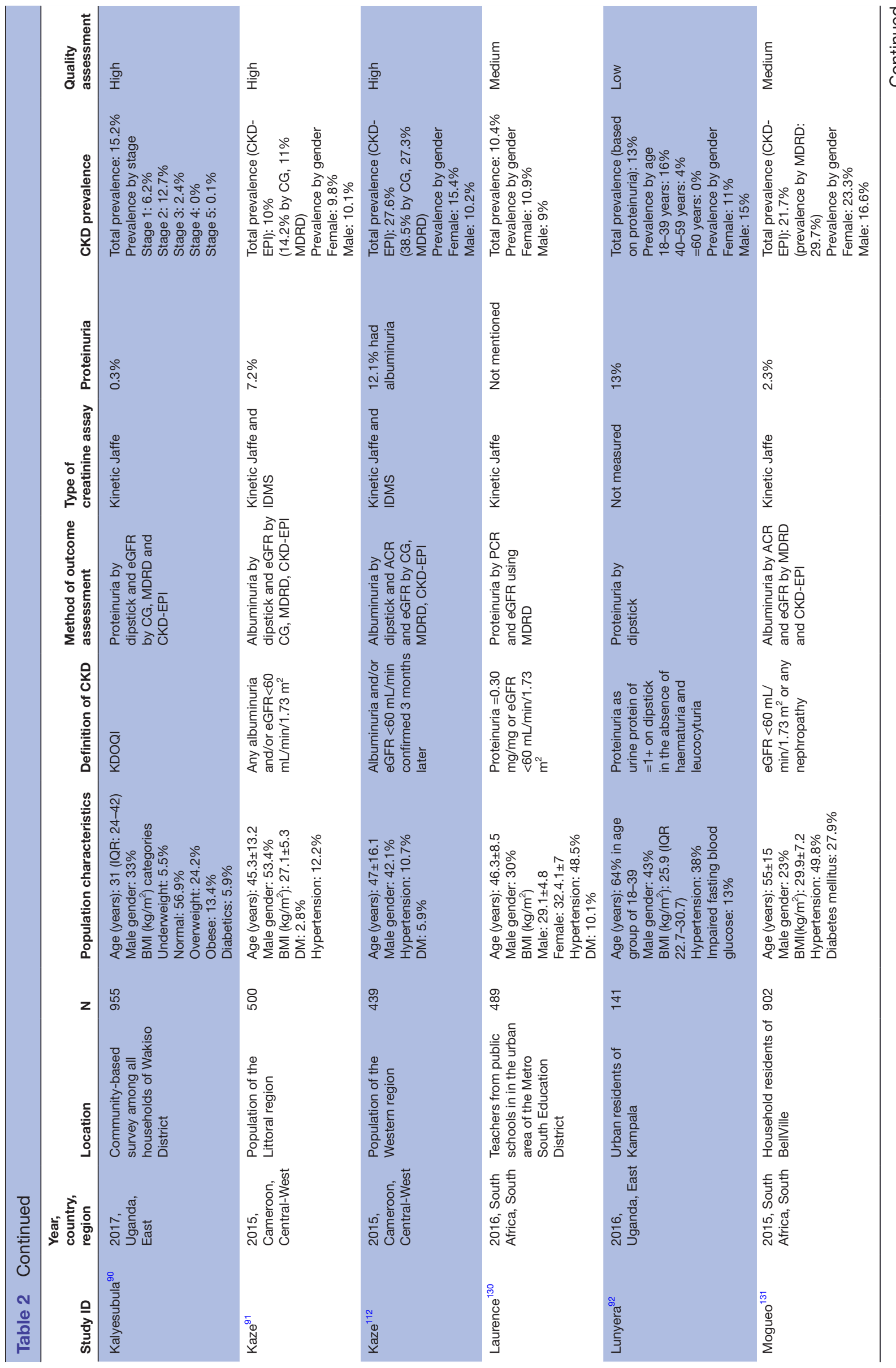




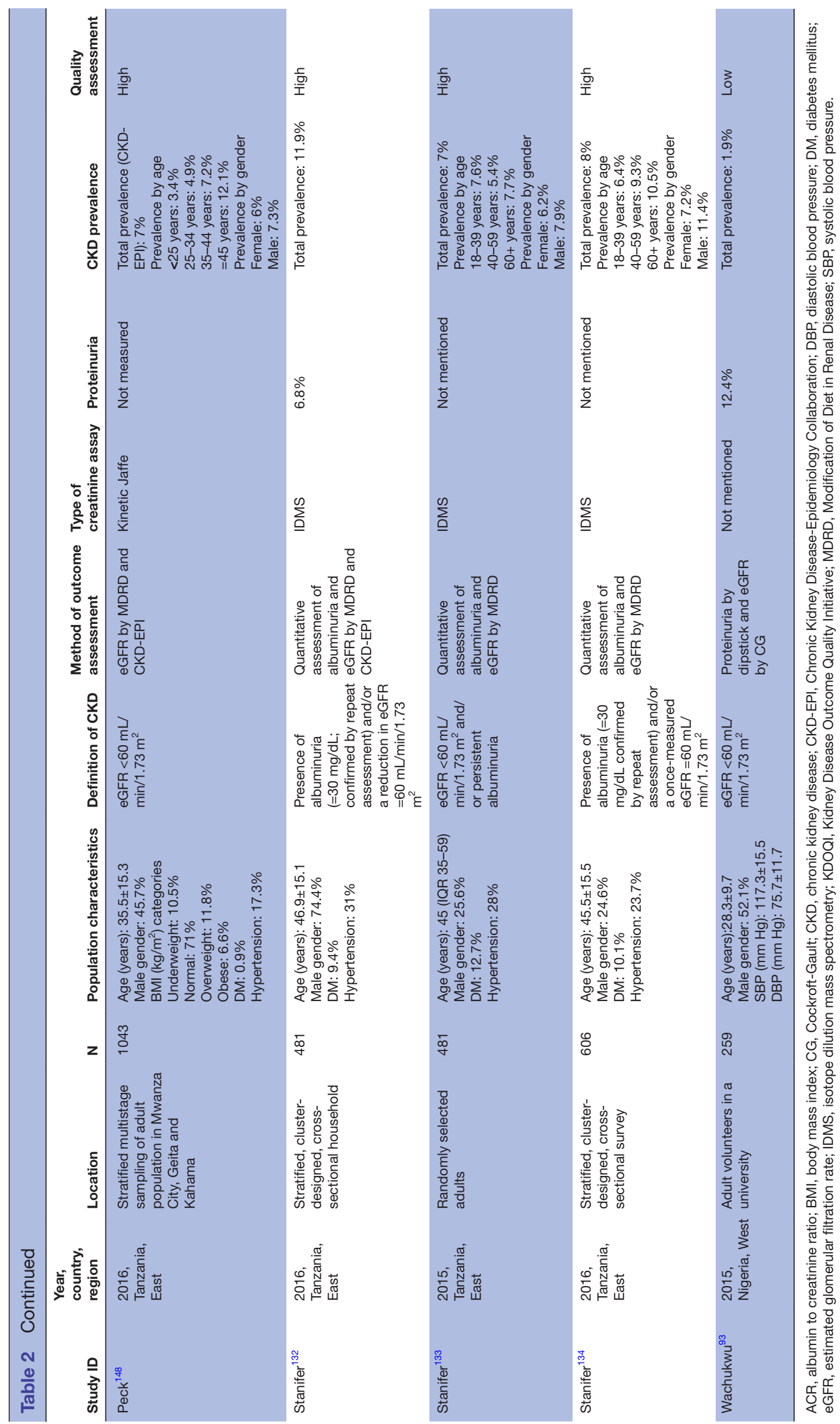




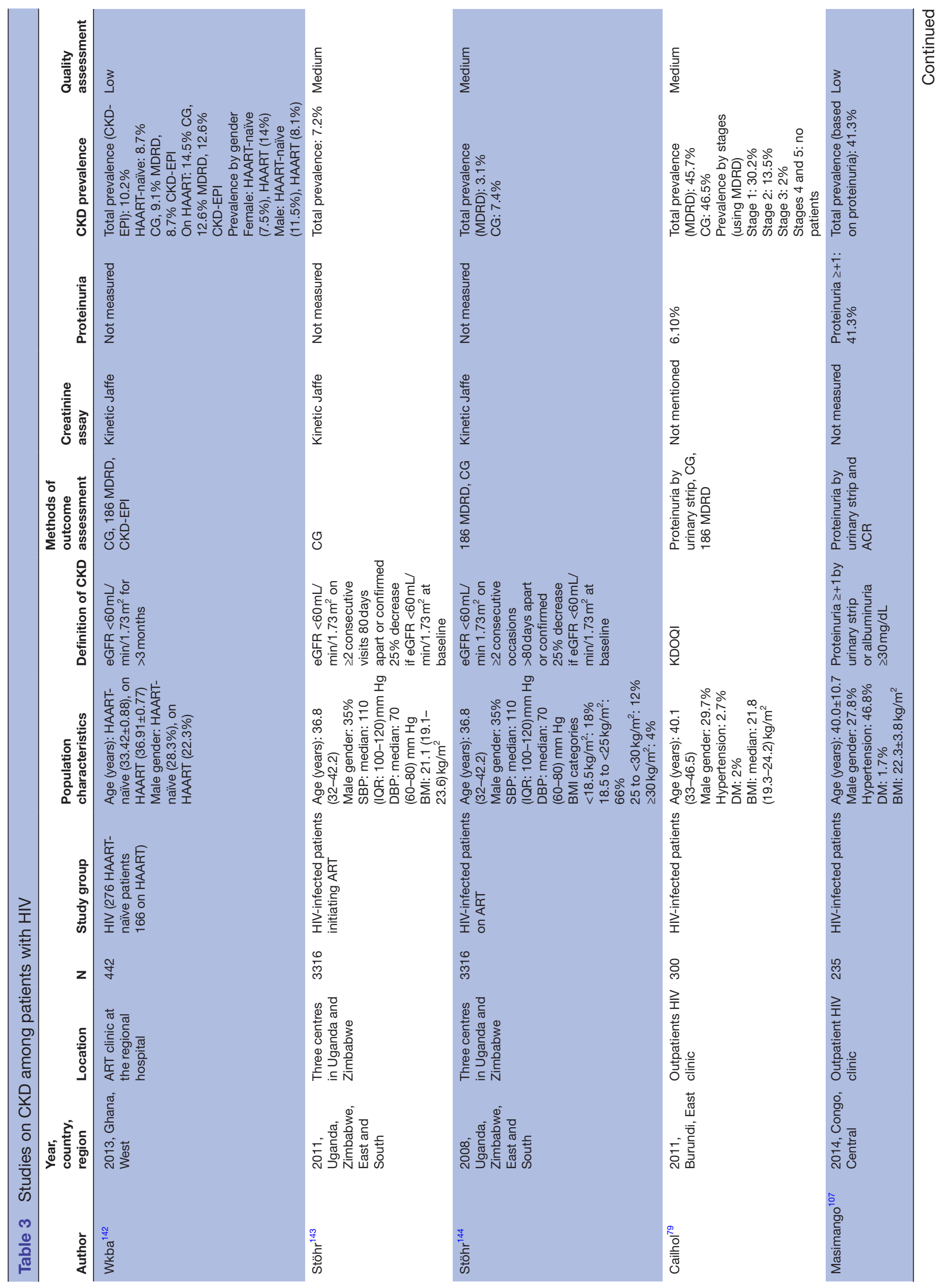



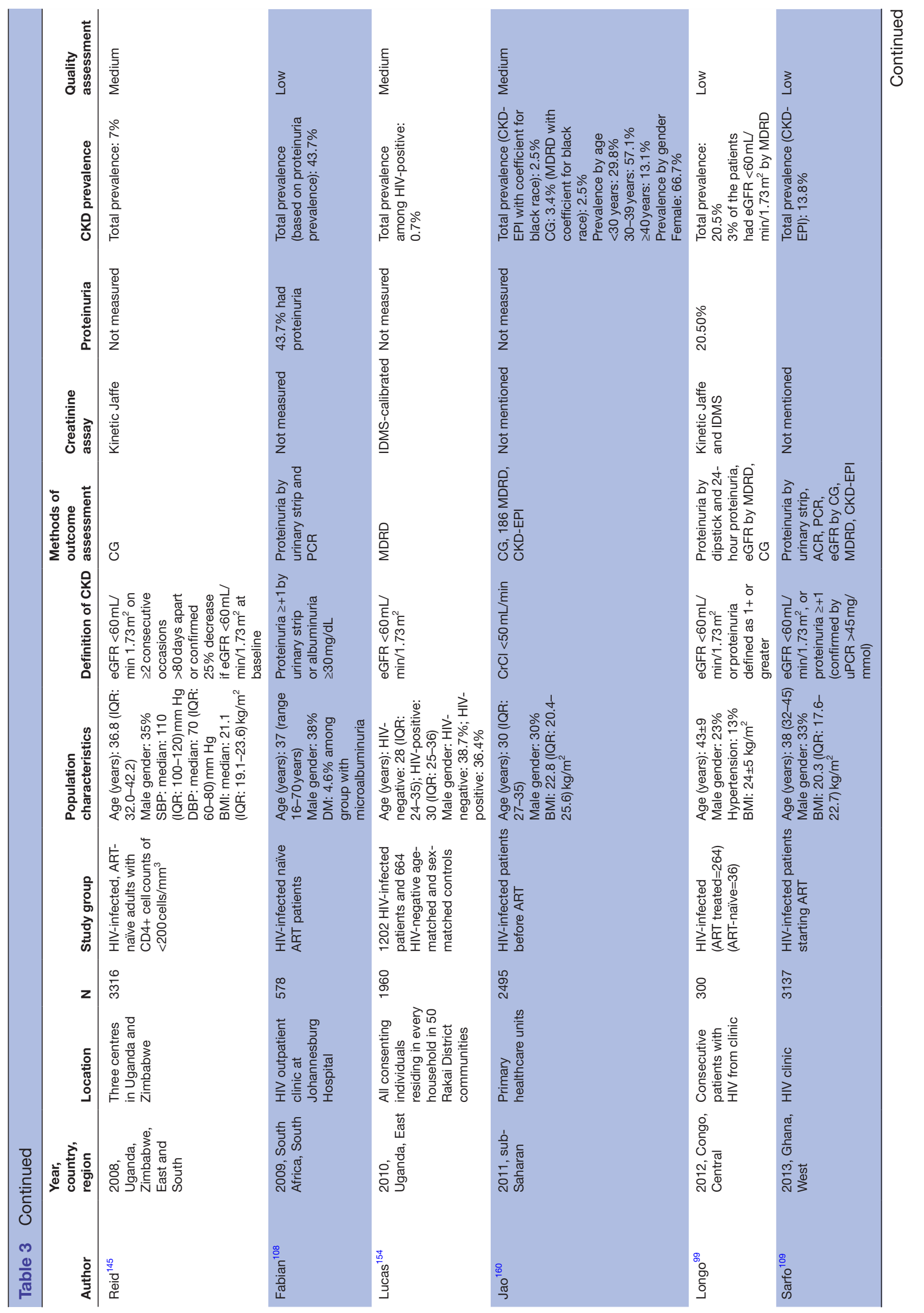


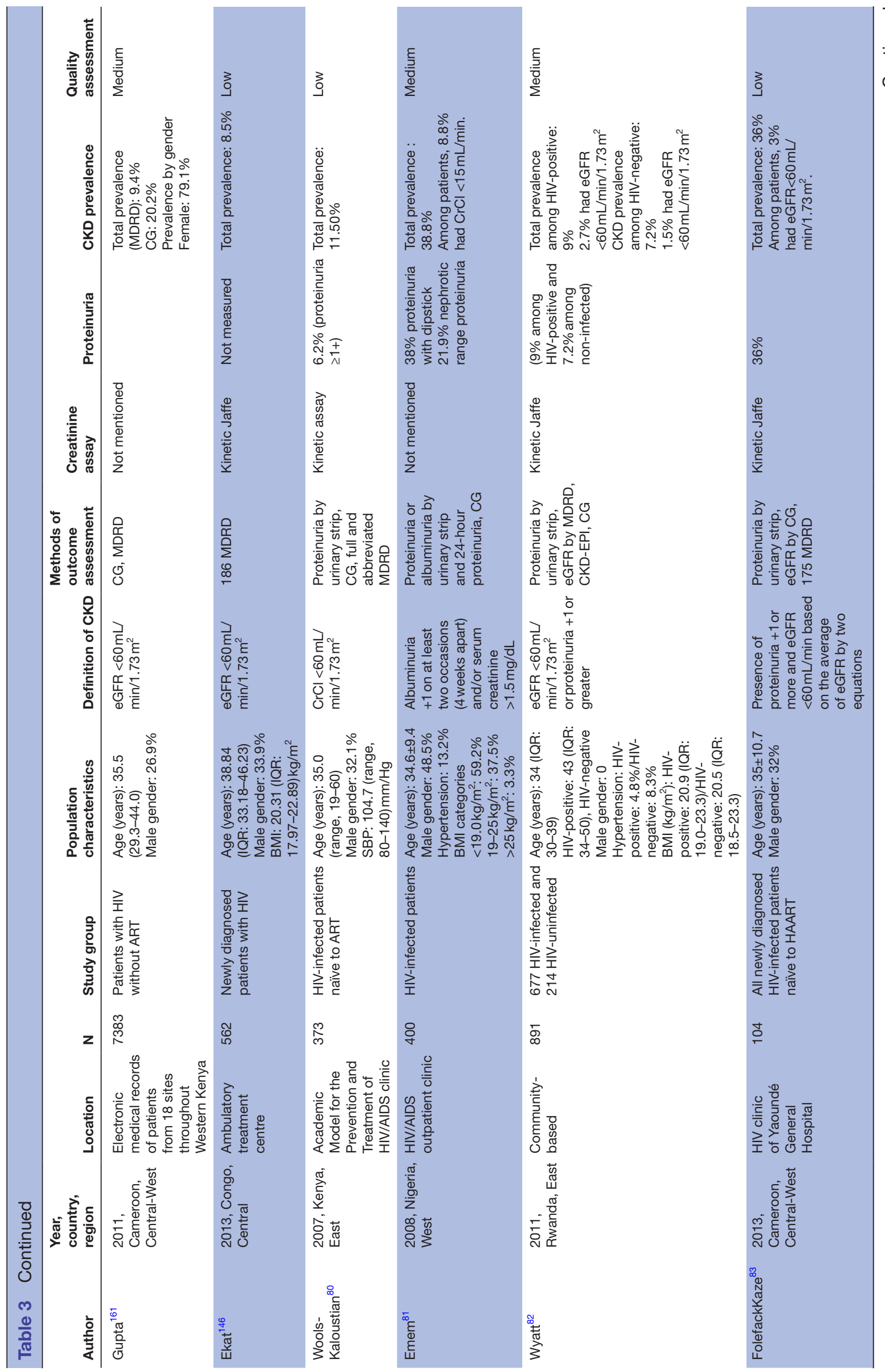









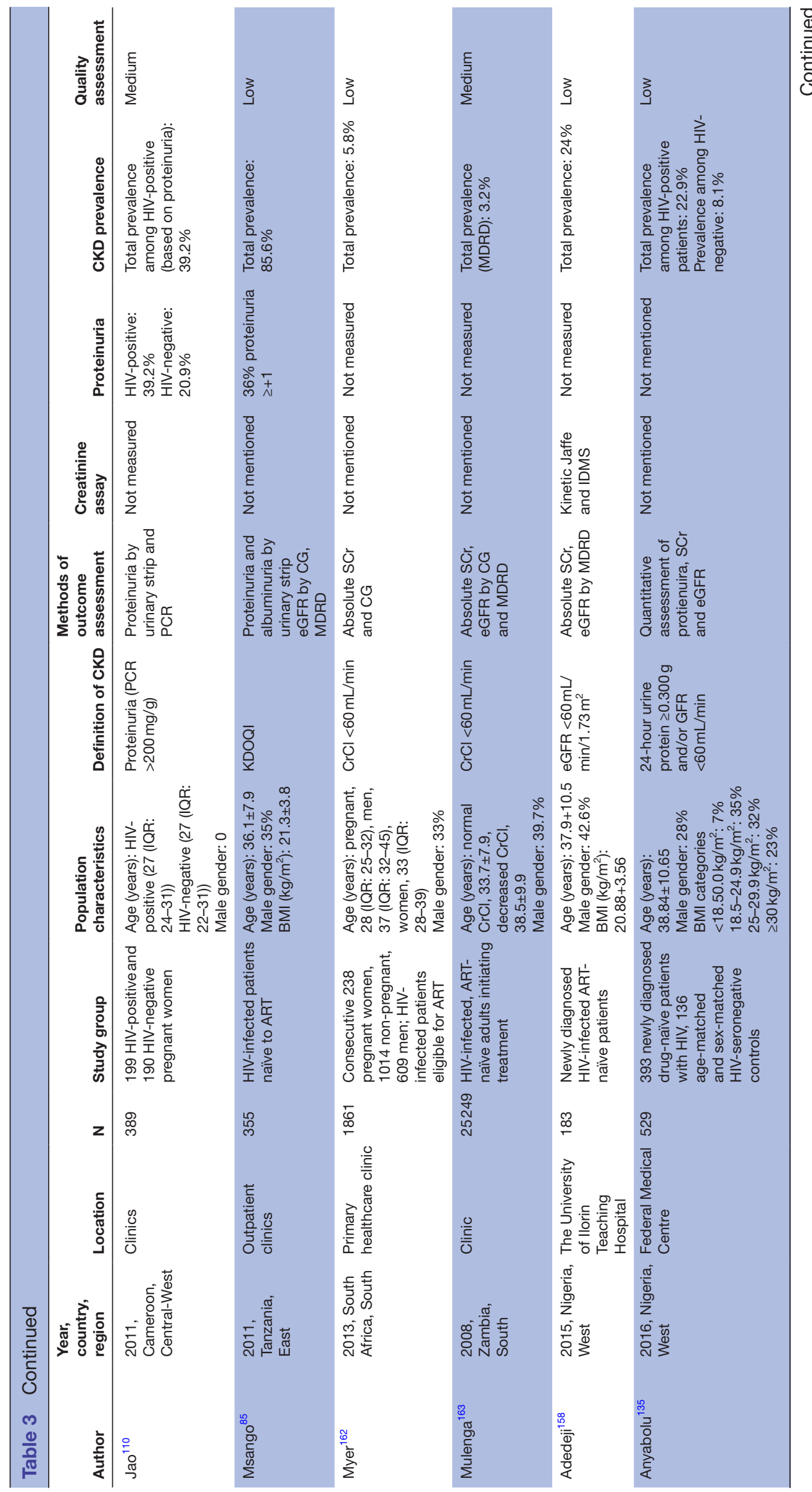




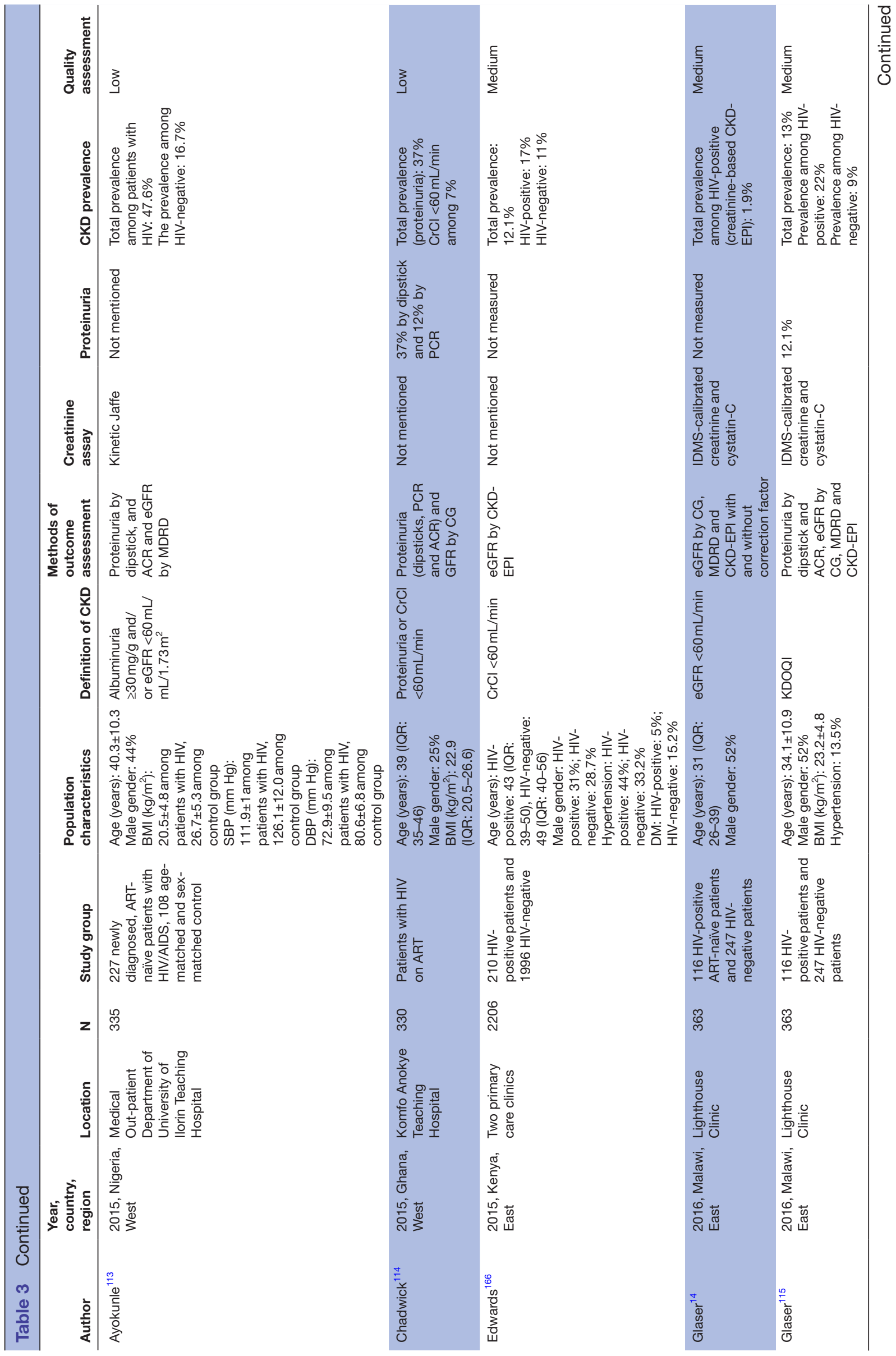




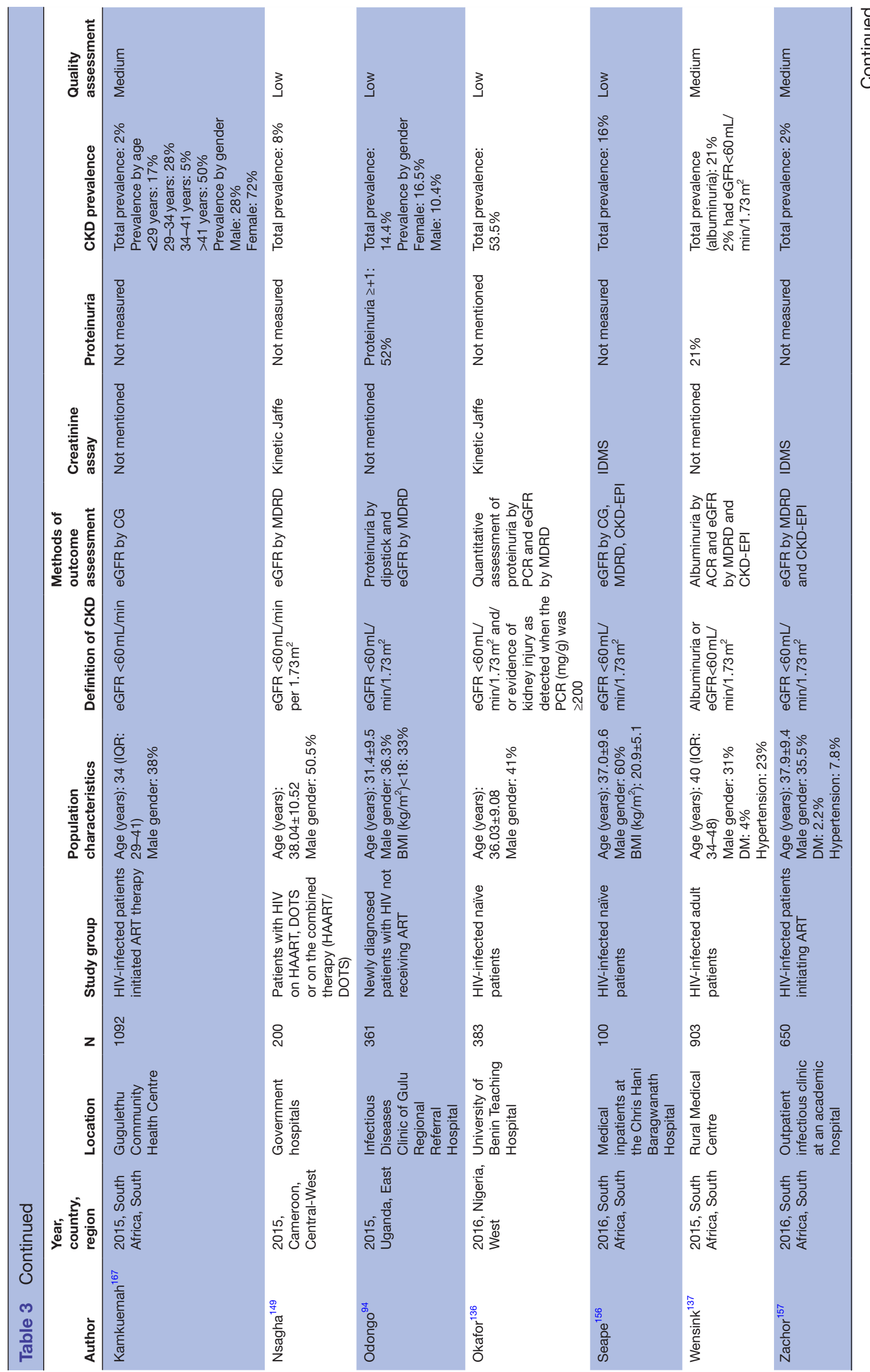


82-84 869199100105106109 112-114 121 130-137 141 Proteinuria/albuminuria was used alone to identify CKD in 14 studies. ${ }^{73-75}$ 778792107108110123128129138140 KDOQI staging ${ }^{168}$ of CKD was used in 13 studies. 1325297985909798115116122124126 The serum creatinine level (either doubling, or an increase above a certain threshold) was considered to be a marker of the presence of CKD in four studies. ${ }^{89} 104120165$ In 16 studies, the definition of CKD was either not mentioned or was defined in various ways, including personal history, creatinine clearance $(\mathrm{CrCl}) \leq 50 \mathrm{~mL} / \mathrm{min}$, clinical manifestations, the presence of albuminuria, elevated serum creatinine and the average of two measurements of eGFR $<90 \mathrm{~mL} / \mathrm{min} / 1.73 \mathrm{~m}^{2}{ }^{1}$. $2728308188101-103118125127147160169$ 170

\section{Paper quality}

Paper quality was high in 16 studies. $^{1325} 7590919798105$ 106112116 132-134 148155 Thirty-five studies were of medium quality. $^{12} 142629737477-79818296110111115117128130131137141$ 143-145 150-152 154 157 159-161 163166167 The rest of the studies were of low quality.

\section{Prevalence of CKD}

The included medium-quality/high-quality studies in the general population in Africa provided estimates of CKD prevalence by disparate criteria (table 2). The prevalence of CKD ranged from $2 \%$ to $41 \%$ (pooled prevalence: $10.1 \%$; $95 \%$ CI $9.8 \%$ to $10.5 \%$ ). The prevalence was reported to range from $2 \%$ to $41 \%$ (pooled estimate: $16.5 \%$ ) in the West/Central-West, followed by the Central region where the prevalence ranged from $12 \%$ to $17 \%$ (pooled estimate: $16 \%$ ), in the Southern where the CKD prevalence range was 6\%-29\% (pooled estimate: 12.2\%), in Eastern where the prevalence ranged from $7 \%$ to $15 \%$ (pooled estimate: $11.0 \%$ ), and in the North where the prevalence ranged from $3 \%$ to $13 \%$ (pooled estimate: $4 \%$ ) (figure 2). In sub-Saharan Africa, the prevalence ranged from $2 \%$ to $14 \%$ (pooled prevalence: $14.02 \%$; $95 \%$ CI $13.5 \%$ to $14.5 \%$ ). In studies defining CKD as eGFR $<60 \mathrm{~mL} / \mathrm{min}$, the prevalence of CKD ranged from $7 \%$ to $29 \%$ (pooled estimate: 13.2\%), while in those who adopted the combined criterion GFR $<60 \mathrm{~mL} / \mathrm{min} / 1.73 \mathrm{~m}^{2}$ and $/$ or the presence of proteinuria or albuminuria, the prevalence ranged from $3 \%$ to $22 \%$ (pooled estimate: $5.6 \%$ ). When defined according to KDOQI, the prevalence ranged from $2 \%$ to $28 \%$ (pooled estimate: $10.8 \%$ ). Finally, in studies reporting on proteinuria/albuminuria only, the prevalence ranged from 3\% to $41 \%$ (pooled estimate: $18.9 \%$ ). The CKD prevalence for each age or gender group was not reported in the majority of the studies. In online supplementary figure 1 we show graphically the relationship between gender and age and CKD prevalence in the medium-high-quality studies of this systematic review.

Among patients with HIV (table 3), the prevalence of CKD in the 18 medium-quality studies ranged from $1 \%$ to $46 \%$ (pooled prevalence: $5.6 \%$; $95 \%$ CI $5.4 \%$ to $5.8 \%)$. The prevalence of CKD in the West/Central West 


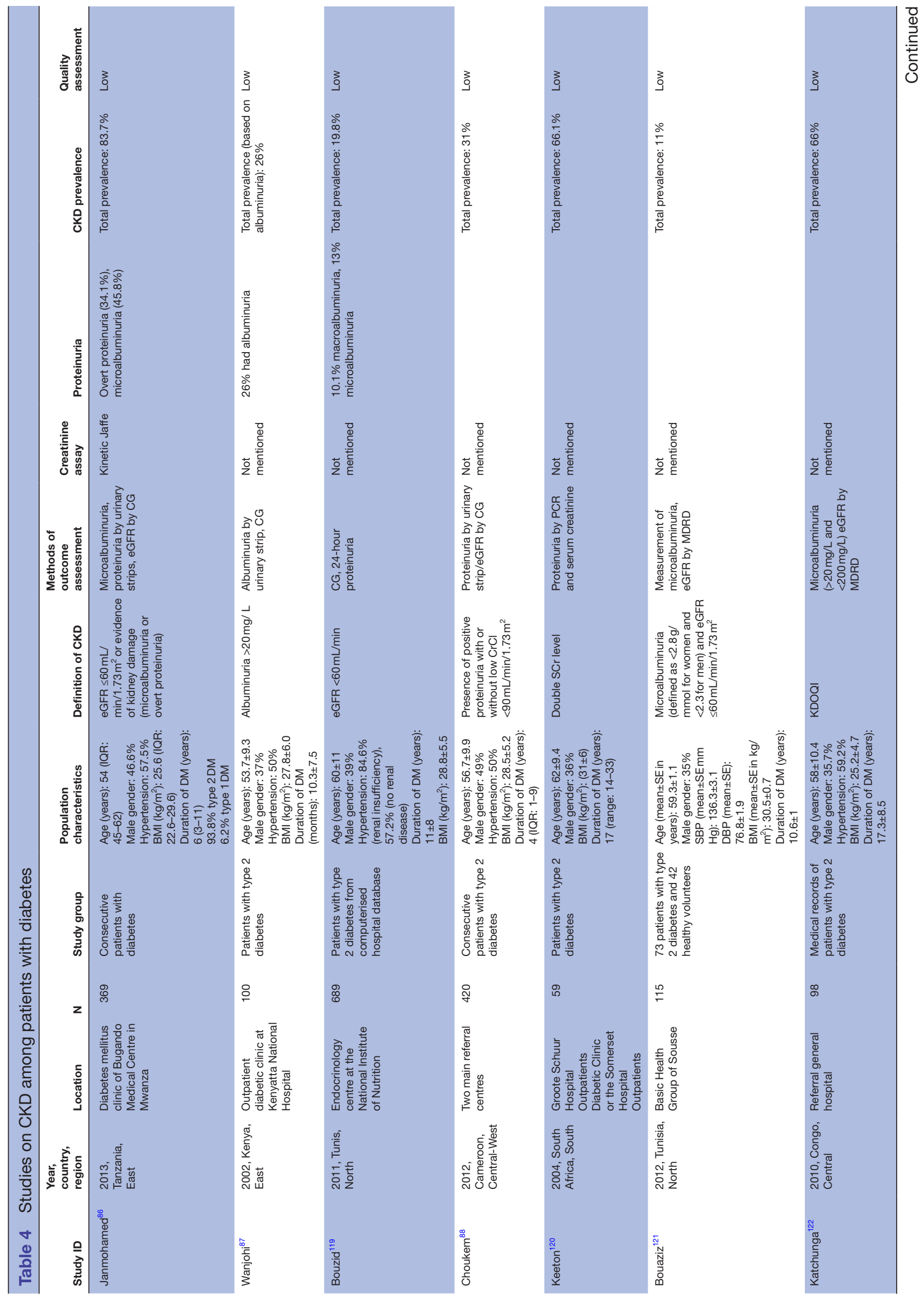




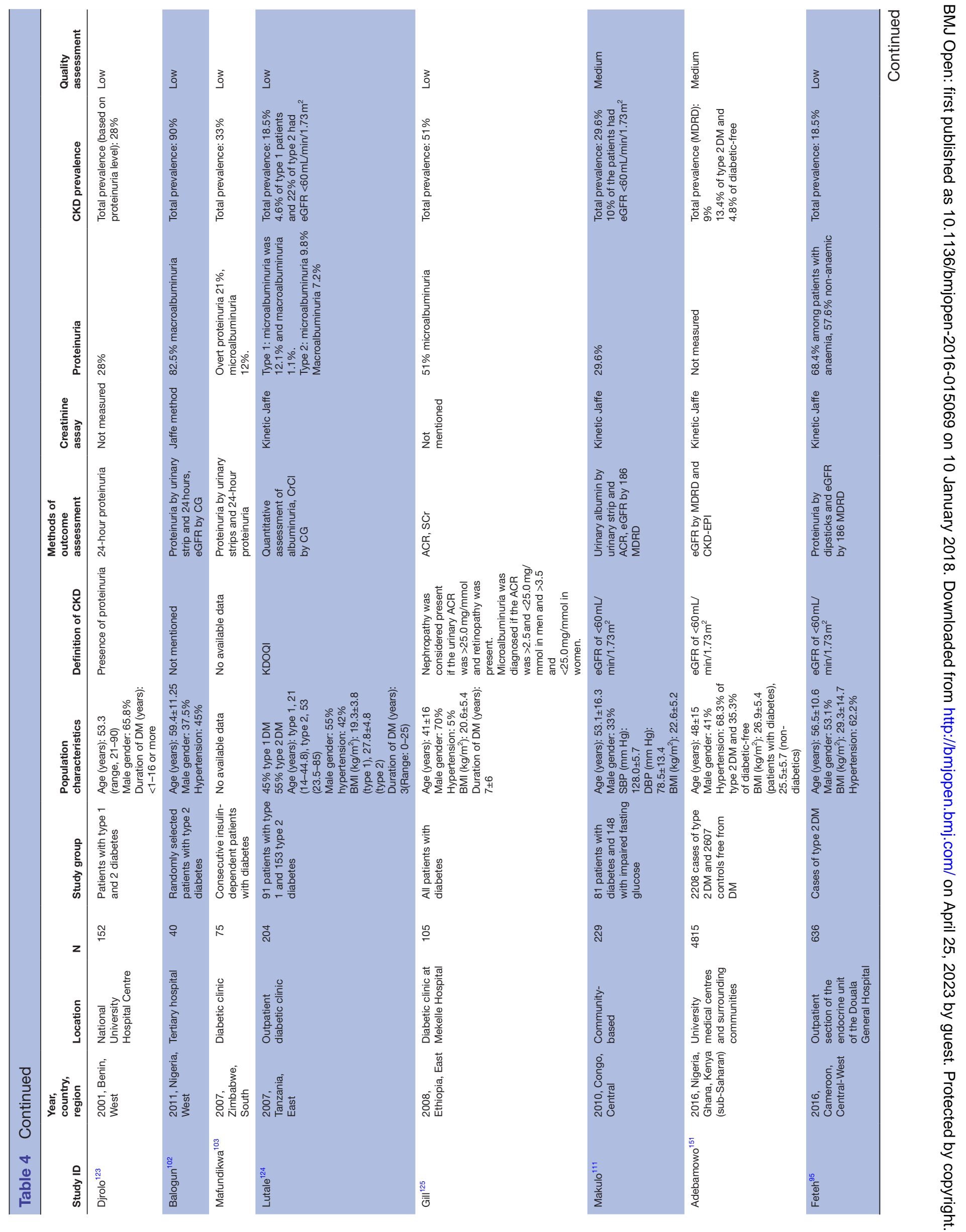




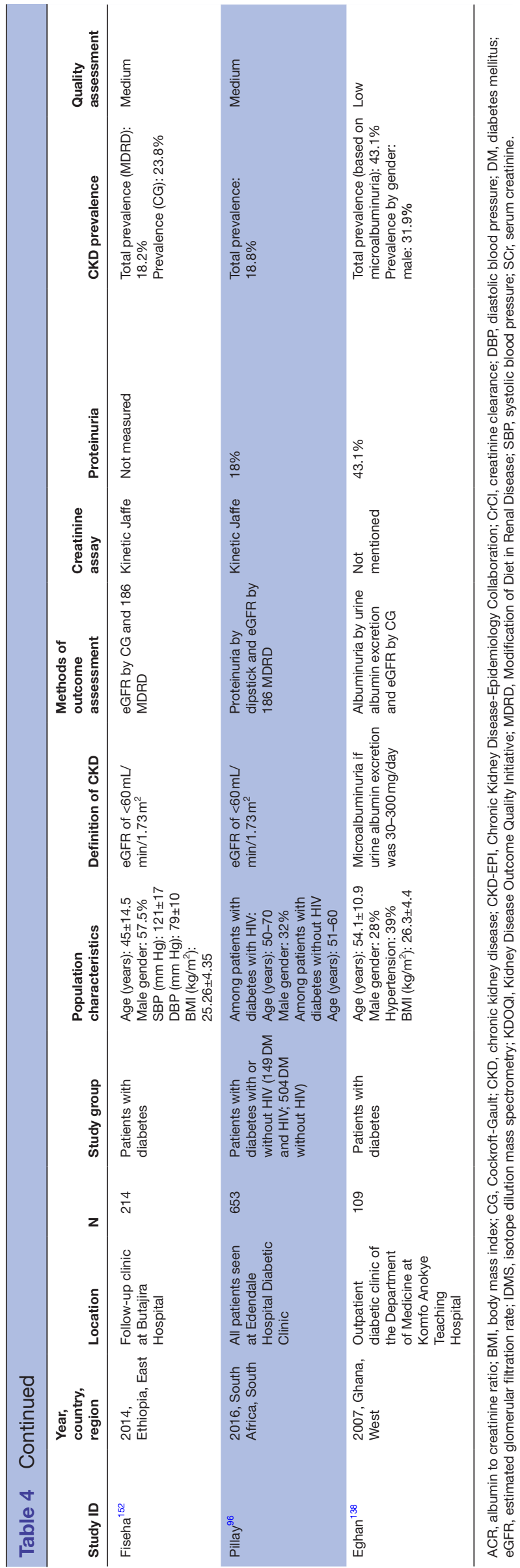

macro-areas, which ranged from $9 \%$ to $39 \%$ (pooled estimate: $11.6 \%$ ), and the East macro-areas, where the prevalence ranged from $1 \%$ to $46 \%$ (pooled estimate: $11.2 \%$ ), had seemingly similar figures, which were higher than in the South $(3.5 \%)$ macro-areas. Based on the treatment status, the prevalence of renal dysfunction ranged from $1 \%$ to $47 \%$ (pooled prevalence: $9.9 \%$; $95 \%$ CI $9.4 \%$ to $10.4 \%$ ) among patients with HIV not receiving treatment, while it ranged from $7 \%$ to $33 \%$ (pooled prevalence: $5.2 \%$; $95 \%$ CI $5.0 \%$ to $5.4 \%$ ) among patients with HIV on antiretroviral therapy. The prevalence was reported to be $5.7 \%$ (range: $3.1 \%-7.2 \%$ ) among the three studies done in both the East and South macro-areas and 2.5\% from the study done in the sub-Saharan area. According to the definition, the prevalence of CKD ranged from $1 \%$ to $18 \%$ (pooled estimate: $4.7 \%$ ) in studies that defined CKD as eGFR $<60 \mathrm{~mL} / \mathrm{min}$. In studies that defined CKD as eGFR $<60 \mathrm{~mL} / \mathrm{min} / 1.73 \mathrm{~m}^{2}$ and/or the presence of proteinuria or albuminuria, the CKD prevalence ranged from $9 \%$ to $21 \%$ (pooled estimate: $5.6 \%$ ). There are other four studies that defined CKD based on either the presence of proteinuria, $\mathrm{KDOQI}, \mathrm{CrCl}<50 \mathrm{~mL} / \mathrm{min}$, or albuminuria and serum creatinine. In these four studies, the prevalence of CKD ranged from $3 \%$ to $46 \%$ (pooled estimate: $12.6 \%$ ). The CKD prevalence for each age or gender group was not reported in the majority of the studies. In online supplementary figure 1 we show graphically the relationship between gender and age and CKD prevalence among patients with HIV in the medium-highquality studies.

Among patients with diabetes (table 4, all studies are of low quality except for four with medium quality), the prevalence of CKD ranged from $11 \%$ to $90 \%$ (pooled prevalence: $24.7 \%$; $95 \%$ CI $23.6 \%$ to $25.7 \%$ ). The highest prevalence was in the Eastern, which ranged from $18 \%$ to $84 \%$ (pooled estimate: $46.9 \%$ ), followed by the Central, where the CKD prevalence ranged from $30 \%$ to $66 \%$ (pooled estimate: $40.8 \%$ ). In the West/ Central-West, CKD prevalence ranged from $18 \%$ to $90 \%$ (pooled estimate: 27.7\%), while in the South the CKD prevalence ranged from $18 \%$ to $66 \%$ (pooled estimate: $23.0 \%$ ), and in the North CKD prevalence ranged from $11 \%$ to $20 \%$ (pooled estimate: $18.9 \%$ ). One study done in sub-Saharan reported that the prevalence was $13 \%$. Among patients with diabetes, CKD prevalence ranged from $11 \%$ to $83 \%$ (pooled estimate: $51.8 \%$ ) when CKD was defined as eGFR $<60 \mathrm{~mL} / \mathrm{min} / 1.73 \mathrm{~m}^{2}$ and/or the presence of proteinuria or albuminuria. When CKD was defined based on proteinuria/albuminuria, CKD prevalence ranged from $26 \%$ to $51 \%$ (pooled estimate: $36.3 \%$ ). In patients with diabetes who had CKD based on eGFR $<60 \mathrm{~mL} / \mathrm{min} / 1.73 \mathrm{~m}^{2}$, the prevalence ranged from $13 \%$ to $30 \%$ (pooled estimate: $16.6 \%$ ). When KDOQI was used to define CKD, the prevalence of CKD ranged from $19 \%$ to $66 \%$ (pooled estimate: $34.2 \%$ ). The CKD prevalence for each age or gender group was not reported in the majority of the studies. In online supplementary figure 1 we show graphically the relationship between gender and 


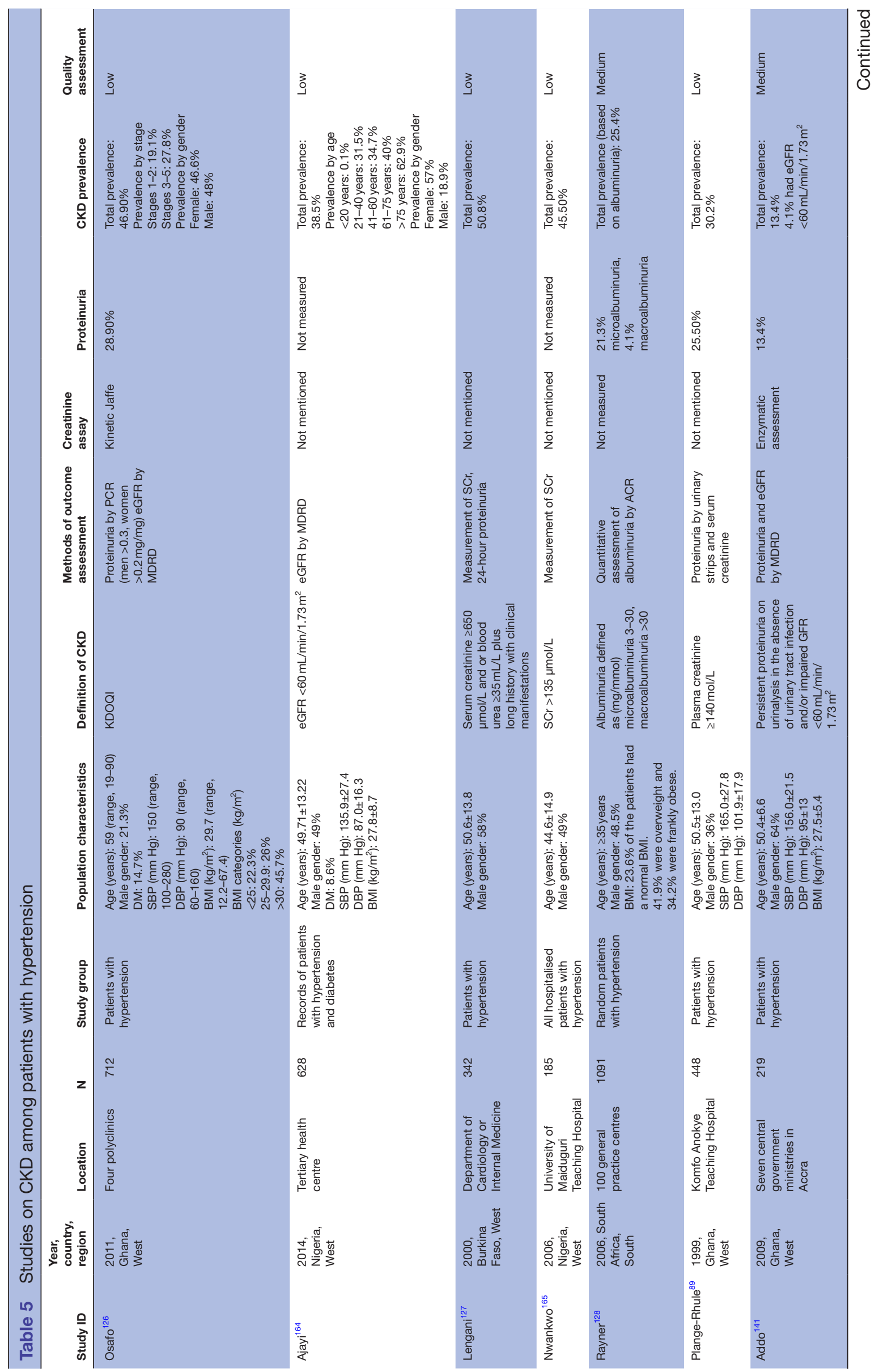




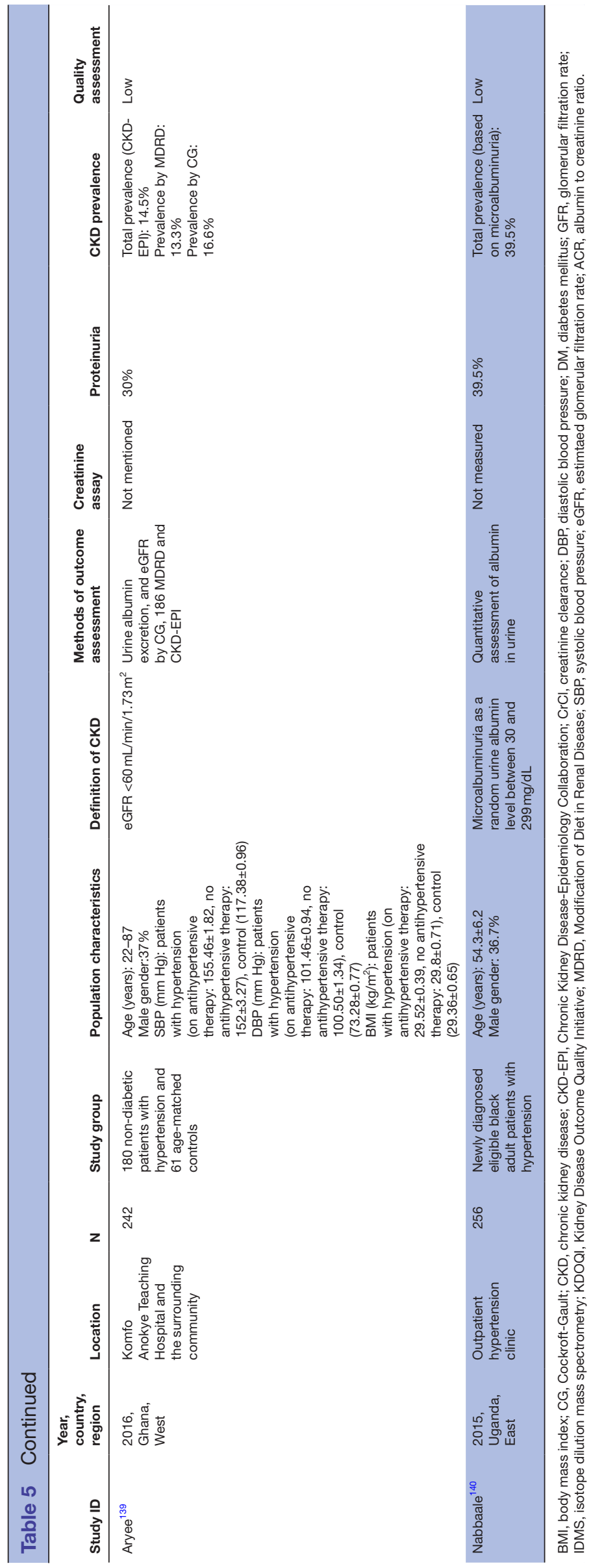




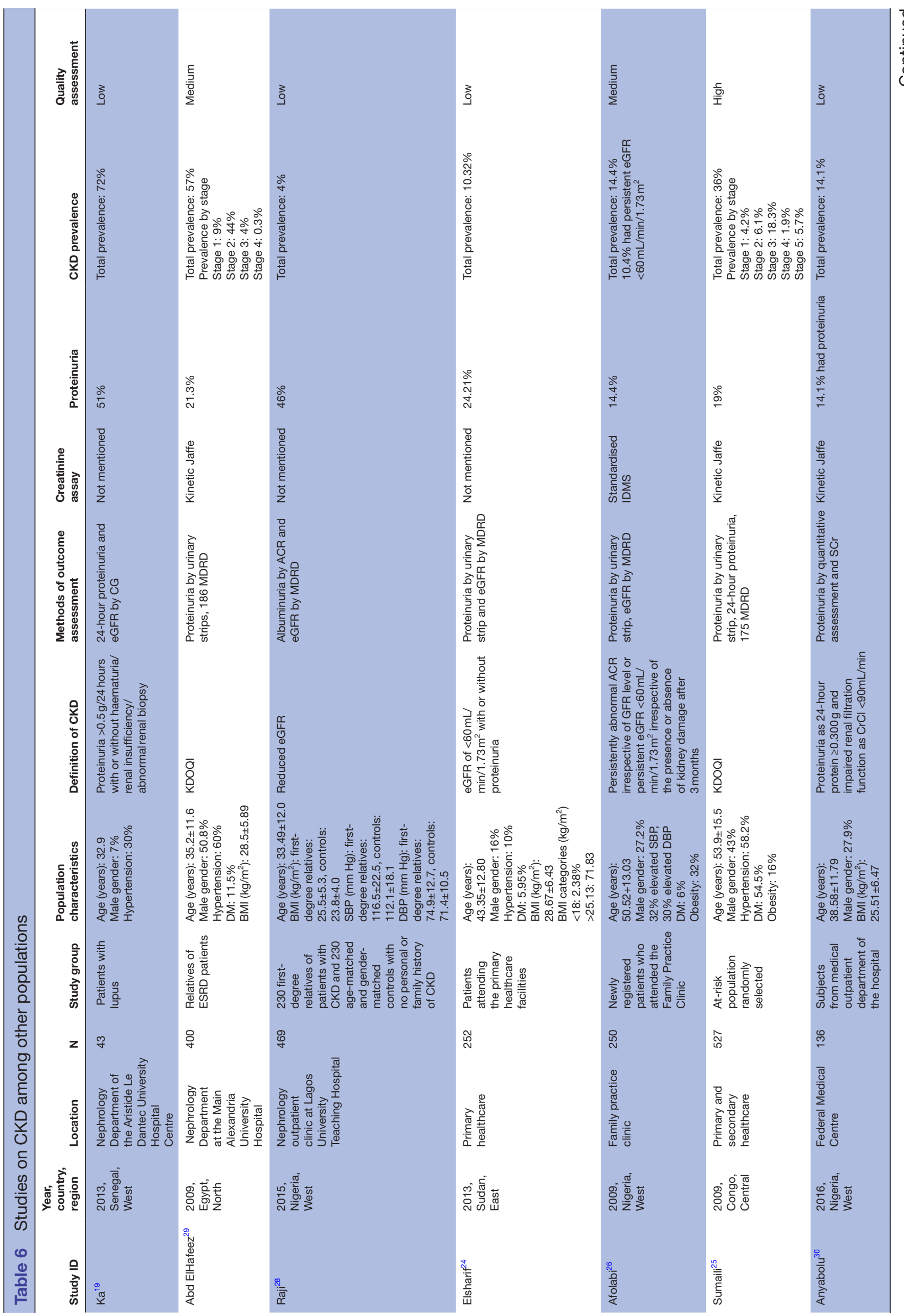

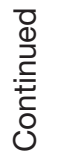




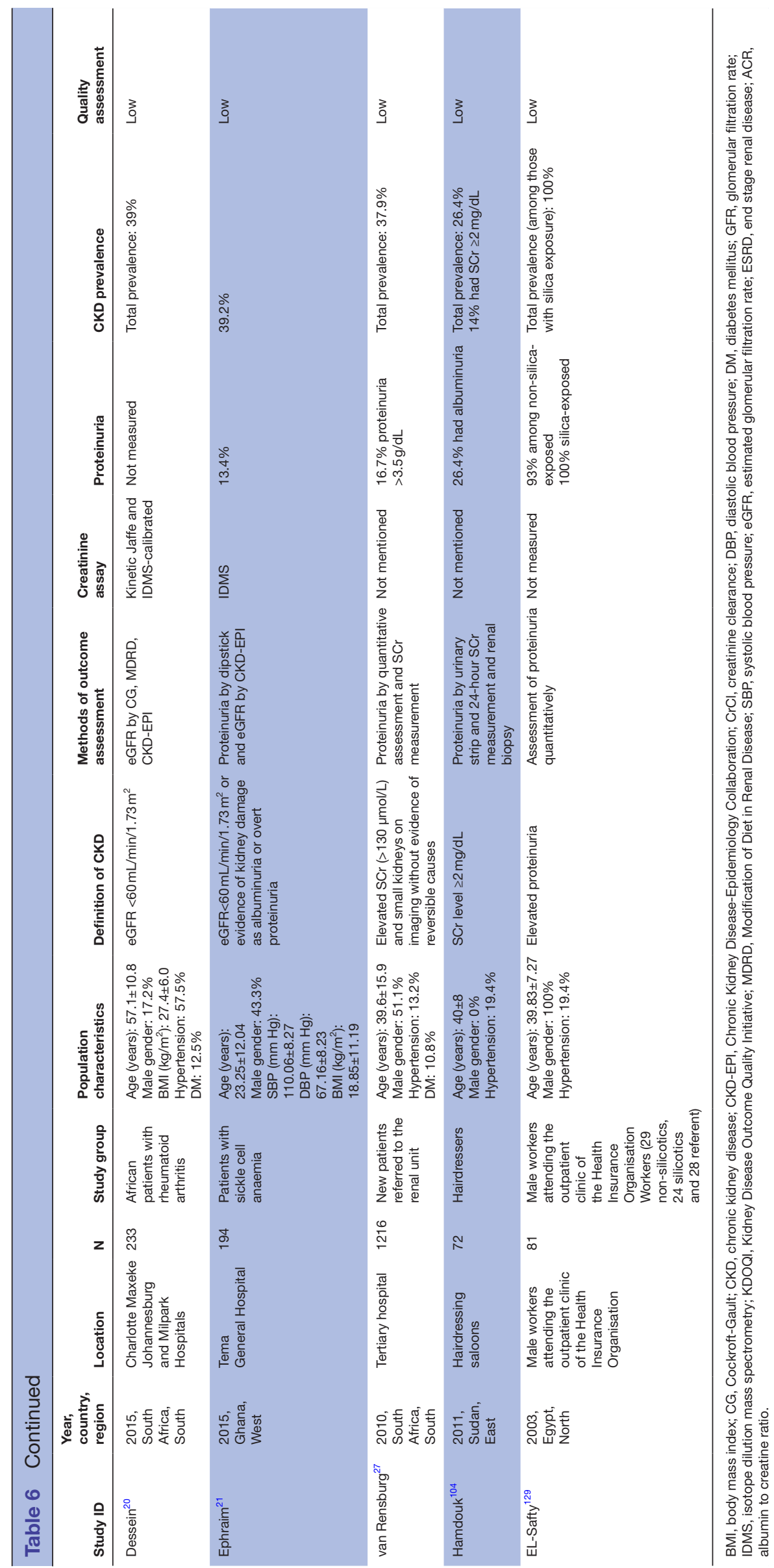




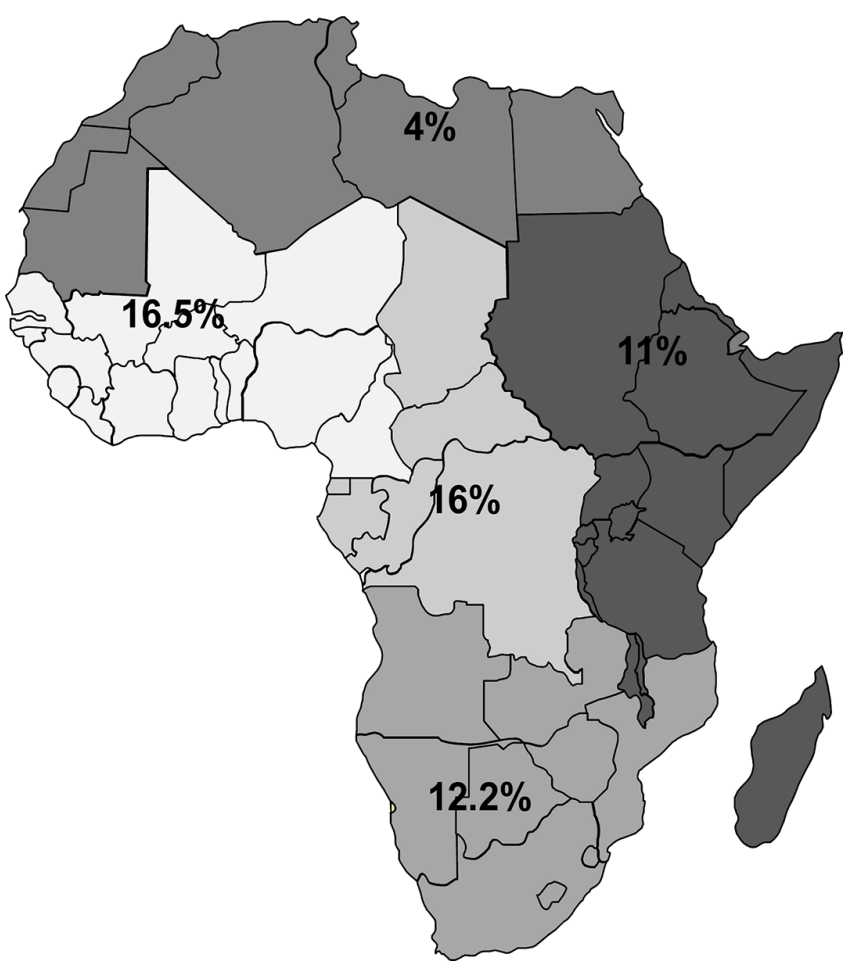

Figure 2 Prevalence of chronic kidney disease among the entire general population. Estimates from this figure should be presented with caution as it is bound to be imprecise and inaccurate due to its tentative way of estimation.

age and CKD prevalence among patients with diabetes in the included studies.

The prevalence of CKD among patients with hypertension (table 5, 9 studies; all of low quality except for two with medium quality) ranged from $13 \%$ to $51 \%$ (pooled prevalence: $34.5 \%$; $95 \%$ CI $34.04 \%$ to $36 \%$ ). The highest prevalence was reported from one study in the East macro-area $(39.5 \%)$, followed by the West/ Central-West, where the prevalence ranged from $13 \%$ to $51 \%$ (pooled estimate: $37.7 \%$ ). In South Africa, the CKD prevalence reported from one study was $25.4 \%$. No data were found for other African macro-areas. In studies that defined CKD as eGFR $<60 \mathrm{~mL} / \mathrm{min} / 1.73 \mathrm{~m}^{2}$, the prevalence of CKD ranged from $38.5 \%$ to $40 \%$ (pooled estimate: $38.9 \%$ ). When serum creatinine was used to define $\mathrm{CKD}$, the prevalence ranged from $30 \%$ to $51 \%$ (pooled estimate: $40.3 \%$ ). When CKD was defined according to albuminuria/proteinuria, the prevalence of CKD ranged from $15 \%$ to $25 \%$ (pooled estimate: $23.6 \%$ ). In one study, CKD was defined according to KDOQI criteria and it was prevalent among $47 \%$ of patients with hypertension. The CKD prevalence for each age or gender group was not reported in the majority of the studies. In online supplementary figure 1 we show graphically the relationship between gender and age and CKD prevalence among patients with diabetes in the included studies.

Among other patient populations (studies reported in table 6), almost three-quarters of patients with lupus had CKD (prevalence $=72.0 \%$ ) based on low-quality study. ${ }^{19}$ Hospital-based surveys revealed that (the calculation was based on the total prevalence reported from all studies including three of high-medium quality and four of low quality in the same table) more than one-third of patients attending either primary care centres or tertiary hospitals had CKD (range: $11 \%-57 \%$, pooled prevalence: $36 \%$, $95 \%$ CI $34.4 \%$ to $37.7 \%$ ). In hospital-based studies, when CKD was defined as eGFR $<60 \mathrm{~mL} / \mathrm{min} / 1.73 \mathrm{~m}^{2}$ and/or the presence of proteinuria or albuminuria, the prevalence ranged from $10 \%$ to $14 \%$ (pooled estimate: $12.4 \%$ ), while the prevalence ranged from $49 \%$ to $57 \%$ (pooled estimate: $45.1 \%$ ) when CKD was defined according KDOQI. CKD was prevalent among almost $39 \%$ of patients with rheumatoid arthritis ${ }^{20}$ or sickle cell. ${ }^{21}$ The study (low quality) conducted among hairdressers exposed to paraphenylenediamine ${ }^{104}$ reported that $26.4 \%$ of these subjects had renal impairment. Of note, $100 \%$ of silica-exposed workers experienced proteinuria (reported from low-quality study). ${ }^{129}$

\section{Causes of CKD}

Forty-two studies were conducted specifically to clarify the underlying cause of $\mathrm{CKD}^{31-72}$ (online supplementary table 2). The diagnosis was biopsy-proven in 17 studies. $^{33}$ 3941 43-45 485455586063 67-70 72 Vascular/hypertensive sclerosis was the main cause of CKD (16\%), followed by diabetic nephropathy (15\%), chronic glomerulonephritis $(13 \%)$, tubulointerstitial/obstructive $(8 \%)$, primary glomerular diseases $(6 \%)$, systemic lupus erythematosus $(3 \%)$ and polycystic kidney disease $(3 \%)$. The causes of CKD were undetermined/miscellaneous causes in one-fifth of the patients $(20 \%)$ (figure 3 ).

\section{DISCUSSION}

This systematic review focuses on the burden of CKD on the entire African continent. We assessed 152 papers published between 1 January 1995 and 7 April 2017 reporting the epidemiology of CKD in the general population and in specific chronic conditions in Africa. The CKD prevalence reported in our review should be interpreted with caution. Our estimates may be affected by the analytical heterogeneity used to measure creatinine and albuminuria. Serum creatinine concentrations are affected by intraindividual variability with over $20 \%$ changes within a 2 -week period ${ }^{171}$ and most Jaffe assays overestimate serum creatinine. ${ }^{172}$ The resulting bias could vary according to the creatinine concentration, specific assay, manufacturer and calibration material used. Although the IDMS calibration standardisation has reduced the bias and improved the inter-laboratory comparability, ${ }^{173}$ the number of studies reported using IDMS was low in Africa. Moreover, CKD prevalence may additionally be influenced by albuminuria assays, which are affected by inter-laboratory differences. ${ }^{174}$ The different equations used to estimate GFR could be a source of bias. The systematic underestimation of measured GFR at higher estimated GFR by the MDRD equation is well known, and may reflect higher creatinine generation in healthy 


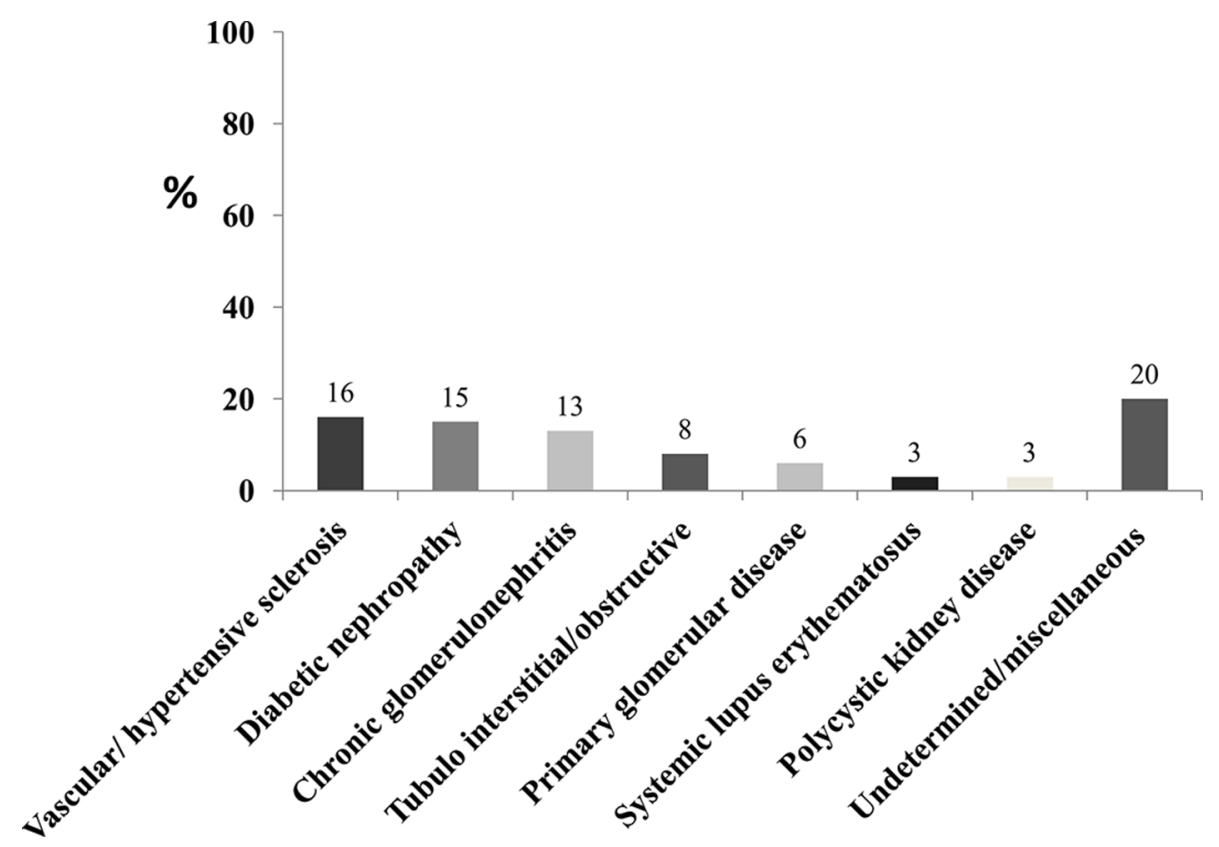

Figure 3 Main causes of chronic kidney disease.

individuals compared with individuals with CKD in whom the MDRD equation was derived. This bias is reduced substantially, but not completely, by the CKD-EPI equation, which was derived from studies including people without CKD. ${ }^{175}$ In addition, differences in sample size, demographics and clinical characteristics are all significant limitations in this systematic review for making accurate estimates of the prevalence of CKD in African countries. Age and gender are well-known determinants of the risk of CKD development, progression and complication. While the prevalence of CKD tends to be higher in women, the disease is more severe in men, who also have a higher risk of all-cause and cardiovascular disease (CVD) mortality across different levels of renal function. However, the risk relationships of reduced eGFR and higher albuminuria with mortality were steeper in women than in men. Moreover, the risk of progression to ESRD at a given eGFR rate and urinary albumin-to-creatinine ratio seemed equivalent in men and women. ${ }^{176}{ }^{177}$ The lack of information on the prevalence of CKD by age and gender in studies included in this systematic review-only $11 \%$ of the included studies reported CKD prevalence by either age or gender groups-limits the value and the reliability of pooled estimates of CKD prevalence in Africa and in its macro-areas. To circumvent this limitation, we showed the prevalence of CKD in the various studies in relationship to the proportion of men and age in the same studies. However the number of studies is too small for reliably capturing the effect of age and gender on CKD prevalence in Africa. Furthermore, only five studies ${ }^{79} 142-145$ assessed the KDOQI chronicity criterion, which is a fundamental element of the current definition of CKD by this organisation. A single elevated serum creatinine, reduced eGFR or an abnormal urinalysis should initially be viewed as a screening test, and the diagnosis of CKD should be confirmed with repeated tests, additional work-up and clinical judgement. ${ }^{178}$ Thus, estimates in this review should be seen as a pragmatic attempt to evaluate the dimension of CKD as a public health issue on the African continent.

CKD is now considered to be an important component of the epidemic of non-communicable diseases in economically developed and low-income/middle-income countries alike. In a seminal meta-analysis published in 2014, Stanifer $e t a \theta^{\dagger}$ for the first time drew attention to the public health relevance of CKD in the sub-Saharan Africa, a vast area comprising 85\% (947.4 million) of the whole African population. ${ }^{9}$ In the present systematic review, the lowest prevalence of CKD (4\%) was reported in the Northern Africa macro-area, including Egypt, Libya, Tunisia, Algeria, Morocco, the Western Sahara and Mauritania, and the highest $(16.5 \%)$ was observed in West/CentralWest Africa, which includes Benin, Burkina Faso, the island nation of Cape Verde, Gambia, Ghana, Guinea, Guinea-Bissau, Ivory Coast, Liberia, Mali, Mauritania, Niger, Nigeria, Cameroon, the island of Saint Helena, Senegal, Sierra Leone, São Tomé and Príncipe and Togo. The average prevalence in the entire African continent was $10.1 \%$. The global CKD prevalence was reported to be $13.4 \% .{ }^{179}$ In sub-Saharan Africa in Stanifer $e t a l$ s meta-analysis, the prevalence of CKD was $13.2 \%,{ }^{9}$ which is close to that reported in the same area in our review (14.02\%). Among the general population of economically developed countries, CKD has $13.6 \%$ prevalence in the USA. ${ }^{180}$ In Europe, the reported prevalence is lower and more homogeneous, being $8.9 \%$ in the Netherlands, $6.8 \%$ in Italy, $5.2 \%$ in Portugal, $4.7 \%$ in Spain and $3.3 \%$ in Norway. ${ }^{181}$ CKD prevalence in some Asian countries was higher than the estimates in the USA and in Europe, being $17.5 \%$ in Thailand ${ }^{182} 15 \%$ in India, ${ }^{183} 13 \%$ in Japan, ${ }^{184} 11.9 \%$ in Taiwan ${ }^{185}$ and $9.9 \%$ in China. ${ }^{186}$ Overall, the estimated prevalence of CKD at 
the general population level in African countries appears to be comparable and possibly even higher than that reported in other continents. This may be at least in part due to the low-quality data for the prevalence of CKD in Africa related to poor sampling techniques, unreliable kidney function measurements and the different definitions used.

In our review, the prevalence of CKD in surveys based on hospitals or primary care centres $(36 \%)$ is close to that in Swiss primary care centres $(36 \%) .{ }^{187}$

Poverty-related factors such as infectious diseases secondary to poor sanitation, inadequate supply of safe water, environmental pollutants and high concentrations of disease-transmitting vectors continue to play an important role in the development of CKD in low-income countries. Although rates of diabetic nephropathy are rising, chronic glomerulonephritis and interstitial nephritis are among the principal causes of CKD in many countries. ${ }^{188}$

In Africa, infectious diseases such as HIV, bilharziasis, malaria, hepatitis $\mathrm{B}$ and $\mathrm{C}$ represent an almost unique cluster of risk factors responsible for CKD ${ }^{189}$ HIV/AIDS is pandemic in Africa, with a prevalence ranging from $0.5 \%$ in Senegal ${ }^{190}$ to $27.4 \%$ in Swaziland. ${ }^{191}$ The global success in bringing effective antiretroviral treatment (highly active antiretroviral therapy (HAART)) to HIV-infected patients in Africa has determined the emergence of chronic medical illnesses such as HIV-related CKD. ${ }^{192}$ Up to $50 \%$ of kidney diseases in HIV-infected persons result from a wide array of non-HIV-associated nephropathy pathologies, ranging from glomerulonephritis to diabetic nephropathy. ${ }^{193}$ We found that $5.6 \%$ of patients with HIV complained of renal dysfunction. This figure is lower than that reported in economically developed countries such as France, USA, China, Spain and Brazil. ${ }^{194-198}$ CKD was higher among patients with HIV not receiving HAART compared with those on HAART. Variation in the proportion of patients with HIV affected by CKD depends on the heterogeneity in the definition used to determine renal dysfunction, the proportion of the study population on HAART, diverse ethnicities, the associated comorbidities and the nutritional status of the study population. Patients with HIV are more prone to nutritional deficiencies due to malabsorption, impaired oral intake and the wasting syndrome. Increased availability of HAART has led to some improvement of the nutritional status of patients. However, for certain individuals, undernutrition and weight loss persist despite therapy. Malnutrition exacerbates side effects, alters drug pharmacokinetics and impinges on adherence, thereby limiting the beneficial effects of the therapy. ${ }^{199}$ Furthermore, differences in HIV clades or strains in African patients ${ }^{200}$ and genetic factor $^{201}$ may influence the replication capacities within the isolated renal reservoir and thus lead to a diversity in clinical presentations. ${ }^{80}$

Regarding systemic autoimmune diseases such as lupus, a study conducted among patients with lupus from Senegal showed that almost three-quarters $(71.0 \%)$ of the patients with this disease had evidence of renal involvement. ${ }^{19}$ This isolated figure is higher than that reported in other countries. ${ }^{202-204}$ More than one-third (39\%) of patients with rheumatoid arthritis had CKD,${ }^{20}$ which is higher than that reported from Taiwan. ${ }^{205}$

Even though there are no sufficient data to precisely reconstruct historical trends, the profile of CKD causes has changed during the last decades. Interstitial nephritis and glomerulonephritis were the main causes of CKD in North Africa, ${ }^{206}$ and CKD was principally caused by chronic glomerulonephritis and hypertension in East and Tropical Africa. ${ }^{207} 208$ Today, the spectrum of causes of CKD in Africa is dominated by diabetes mellitus and hypertension. ${ }^{209}$ We found that the prevalence of vascular/hypertensive and diabetic nephropathies as a cause of CKD (16\% and 15\%, respectively) exceeded that caused by chronic glomerulonephritis (13\%).

Our review has both strengths and limitations. The major strengths include a thorough systematic search of electronic databases and the inclusion of all comprehensive studies with a transparent assessment of CKD prevalence by two independent reviewers. The fact that our literature search was limited to PubMed and Ovid Medline but did not include the African Index Medicus, like it was done by Stanifer et al in the meta-analysis of CKD in sub-Saharan Africa ${ }^{9}$, is a limitation of our study. Because there was a huge discrepancy in the definitions used to identify CKD, the methods of creatinine measurement, urine protein assessment and in the quality of the reporting, we decided to adopt an inclusive strategy. Our primary interest was to identify all studies conducted among different population groups in Africa providing information on CKD and to reconstruct a tentative scenario of the epidemiological dimension concerning disease in the entire African continent. Methodological limitations notwithstanding this review compiled estimates suggesting that the CKD burden in Africa is at least as concerning as that in economically developed countries. The lack of a consistent definition of CKD makes it difficult to compare the burden of CKD across studies in various countries. Moreover, the failure to demonstrate chronicity when defining CKD is a common limitation of studies investigating CKD prevalence in Africa. It was reported that a single test in time has an extremely poor positive predictive value for confirmation of CKD compared with repeated testing 3 months later. Failure to repeat testing may lead to a significant overestimation of CKD prevalence and underestimation of the burden of CVD in CKD. ${ }^{210}$ In addition, observational studies are subject to bias and residual confounding, which are difficult to account for and there are limitations due to the heterogeneity that arises from differences in age and sex distributions. This poor data quality reported in different studies is considered as a cumbersome problem limiting the accuracy in assessing the burden of CKD in Africa.

In conclusion, CKD in Africa appears to be at least as common as in other continents, and as such it constitutes a true public health priority with major cost burden 
to healthcare systems worldwide. Targeted screening of high-risk groups (including those patients with with hypertension, diabetes mellitus and HIV, and persons with occupational exposures) should likely be instituted as the first step in kidney disease prevention whenever and wherever affordable and feasible. Education to increase awareness of CKD among healthcare workers and patients, and the promotion of healthy lifestyles, should be engrained in preventive programmes. The treatment of hypertension and diabetes mellitus is of obvious relevance. Nurses and other health workers should be trained to manage these conditions at the local level if we are to curb the incidence of CKD and to avert the added burden of CKD complications to diabetes, hypertension and infectious diseases, the deadly trio of risk factors underlying the CKD epidemic in Africa.

Acknowledgements We would like to thank the following professors and physicians for their help in providing the articles we evaluated in our review: Professor Olutayo Alebiosu, Professor Ahmed Donia, Professor Rashad Barsoum, Professor Carel IJsselmuiden, Professor Laurent Forcard, Professor Anatole Laleye, Professor Nestor Pakasa, Professor Imaobong Etuk, Professor Ifeoma Ulasi, Professor Abubakr Abefe Sanusi, Professor Gbenga Ayodele, Professor Raida S Yahya, Professor Mohammed Benghanem Gharbi, Professor Fatma Ben Moussa, Dr Ikechi Okpechi, Dr Alaya Akram, Dr Adebowale Ademola, Dr Oluyombo Rotimi, Dr KS Nayak, Dr Guy Neild, Dr Rasheed Gbadegesin, Dr Sidy Mohamed Seck, Dr Amr El-Husseini Mohamed, Dr Fasika M Tedla, Professor Adewale Akinsola, Professor Olanrewaju Adedoyin, Dr Halle Marie Patrice, Dr Emmanuel Agaba, Professor Miriam Adhikari, Dr BT Bello and Dr Zidane Djelloul.

Contributors SA, DB and CZ: conceptualised and designed the study. SAE, GD and ED: participated in revising the articles included in the review and retrieved the necessary information. DB and GT: supervised the data capture and analysis. SAE, DB and GT: analysed and interpreted the data. SAE, DB and CZ: drafted and critically revised the manuscript. All of the authors read and approved the final manuscript.

Funding SA was granted a European Renal Association-European Dialysis and Transplantation Association (ERA-EDTA) fellowship at CNR-IFC/IBIM, Clinical Epidemiology and Physiopathology of Renal Disease and Hypertension of Reggio Calabria, Italy, and this work was completed during her training. This article was written in the framework of the Advisory Program of the ERA-EDTA YNP (Young Nephrologists' Platform), which is an official body of the ERA-EDTA (European Renal Association-European Dialysis and Transplant Association). SA was an advisee of ERA-EDTA YNP Adviser-Advisee Program (Adviser: DB).

Competing interests None declared.

Provenance and peer review Not commissioned; externally peer reviewed.

Data sharing statement All data are published in the manuscript.

Open Access This is an Open Access article distributed in accordance with the Creative Commons Attribution Non Commercial (CC BY-NC 4.0) license, which permits others to distribute, remix, adapt, build upon this work non-commercially, and license their derivative works on different terms, provided the original work is properly cited and the use is non-commercial. See: http://creativecommons.org/ licenses/by-nc/4.0/

(C) Article author(s) (or their employer(s) unless otherwise stated in the text of the article) 2018. All rights reserved. No commercial use is permitted unless otherwise expressly granted.

\section{REFERENCES}

1. Levey AS, Atkins R, Coresh J, et al. Chronic kidney disease as a global public health problem: approaches and initiatives - a position statement from Kidney Disease Improving Global Outcomes. Kidney Int 2007;72:247-59.

2. Zoccali C, Kramer A, Jager KJ. Epidemiology of CKD in Europe: an uncertain scenario. Nephrol Dial Transplant 2010;25:1731-3.

3. Global, regional, and national age-sex specific all-cause and causespecific mortality for 240 causes of death, 1990-2013: a systematic analysis for the Global Burden of Disease Study 2013. Lancet 2015;385:117-71.

4. Bello AK, Peters J, Rigby J, et al. Socioeconomic status and chronic kidney disease at presentation to a renal service in the United Kingdom. Clin J Am Soc Nephrol 2008;3:1316-23.

5. El Nahas AM, Bello AK. Chronic kidney disease: the global challenge. Lancet 2005;365:331-40.

6. UN World Population Prospects: The 2015 Revision, Key Findings and Advance Tables: United Nations. 2015 http://esa.un.org/unpd/ wpp/publications/files/key_findings_wpp_2015.pdf (accessed 8 Nov 2015).

7. Ad-G A, Unwin N, Agyemang C, et al. Commentary Tackling Africa's chronic disease burden: from the local to the global. 2010.

8. World Health Organization. Global action plan for the prevention and control of noncommunicable diseases 2013-2020. 2013.

9. Stanifer JW, Jing B, Tolan S, et al. The epidemiology of chronic kidney disease in sub-Saharan Africa: a systematic review and meta-analysis. Lancet Glob Health 2014;2:e174-81.

10. Anothaisintawee T, Rattanasiri S, Ingsathit $A$, et al. Prevalence of chronic kidney disease: a systematic review and meta-analysis. Clin Nephrol 2009;71:244-54.

11. Liberati A, Altman DG, Tetzlaff $\mathrm{J}$, et al. The PRISMA statement for reporting systematic reviews and meta-analysis of studies that evaluate health care interventions: explanation and elaboration. Italian Journal of Public Health 2012;6.

12. Matsha TE, Yako YY, Rensburg MA, et al. Chronic kidney diseases in mixed ancestry south African populations: prevalence, determinants and concordance between kidney function estimators. BMC Nephrol 2013;14:75.

13. Eastwood JB, Kerry SM, Plange-Rhule J, et al. Assessment of GFR by four methods in adults in Ashanti, Ghana: the need for an eGFR equation for lean African populations. [Erratum appears in Nephrol Dial Transplant. 2011 Dec;26(12):4153 Note: Emmett, Lynsey [added]; Miller, Michelle A [added]]. Nephrol Dial Transplant 2010;25:2178-87.

14. Glaser N, Deckert A, Phiri S, et al. Comparison of Various Equations for Estimating GFR in Malawi: How to Determine Renal Function in Resource Limited Settings? PLoS One 2015;10:e0130453.

15. Jüni P, Altman DG, Egger M. Systematic reviews in health care: Assessing the quality of controlled clinical trials. BMJ 2001;323:42-6.

16. Whiting P, Rutjes AW, Reitsma JB, et al. The development of QUADAS: a tool for the quality assessment of studies of diagnostic accuracy included in systematic reviews. BMC Med Res Methodol 2003:3:25.

17. Shamliyan $T$, Kane RL, Dickinson S. A systematic review of tools used to assess the quality of observational studies that examine incidence or prevalence and risk factors for diseases. J Clin Epidemiol 2010;63:1061-70.

18. Cohen J. A Coefficient of Agreement for Nominal Scales. Educ Psychol Meas 1960;20:37-46.

19. Ka EF, Cisse MM, Lemrabott AT, et al. [Lupus nephropathy in black patients with systemic lupus erythematosus in Senegal: 43 cases]. Med Sante Trop 2013;23:328-31.

20. Dessein PH, Hsu HC, Tsang L, et al. Kidney function, endothelial activation and atherosclerosis in black and white Africans with rheumatoid arthritis. PLoS One 2015;10:e0121693.

21. Ephraim RK, Osakunor DN, Cudjoe O, et al. Chronic kidney disease is common in sickle cell disease: a cross-sectional study in the Tema Metropolis, Ghana. BMC Nephrol 2015;16:75.

22. Ghahramani N. Silica nephropathy. Int J Occup Environ Med 2010;1:108-115.

23. Sampathkumar K, Yesudas S. Hair dye poisoning and the developing world. J Emerg Trauma Shock 2009;2:129.

24. Elsharif ME, Abdullha SM, Abdalla SM, et al. The magnitude of chronic kidney diseases among primary health care attendees in Gezira state, Sudan. Saudi J Kidney Dis Transpl 2013;24:807-9.

25. Sumaili EK, Cohen EP, Zinga CV, et al. High prevalence of undiagnosed chronic kidney disease among at-risk population in Kinshasa, the Democratic Republic of Congo. BMC Nephrol 2009;10:18.

26. Afolabi MO, Abioye-Kuteyi EA, Arogundade FA, et al. Prevalence of chronic kidney disease in a Nigerian family practice population. $S$ Afr Fam Pract 2009;51:132-7.

27. van Rensburg BW, van Staden AM, Rossouw GJ, et al. The profile of adult nephrology patients admitted to the Renal Unit of the Universitas Tertiary Hospital in Bloemfontein, South Africa from 1997 to 2006. Nephrol Dial Transplant 2010;25:820-4.

28. Raji Y, Mabayoje O, Bello T. Familial clustering of risk factors for cardiovascular disease among first-degree relatives of patients 
with chronic kidney disease in a sub-Saharan African population. Cardiovasc J Afr 2015;26(2 Suppl 1):S11-14.

29. The unrecognized prevalence of chronic kidney disease among family members of end stage renal disease patinets [IEA-EEF abstract 264]. Eur J Epidemiol 2009.

30. Anyabolu EN, Chukwuonye II, Anyabolu AE, et al. A look at risk factors of proteinuria in subjects without impaired renal filtration function in a general population in Owerri, Nigeria. Pan Afr Med $J$ 2016;23:257.

31. El Khayat SS, Hallal K, Gharbi MB, et al. Fate of patients during the first year of dialysis. Saudi J Kidney Dis Transp/ 2013;24:605-9.

32. Seck SM, Diallo IM, Diagne SI. Epidemiological patterns of chronic kidney disease in black African elders: a retrospective study in West Africa. Saudi J Kidney Dis Transpl 2013;24:1068-72.

33. Seck SM, Elhadj FK, Fall S, et al. [Adherence to therapy in subSaharan non-dialysed patients with chronic kidney diseases]. Nephrol Ther 2008;4:325-9.

34. Bourquia A. Société marocaine des maladies rénales. [Autosomal dominant polycystic kidney disease (ADPKD). in Morocco. Multicenter study about 308 families]. Nephrologie 2002;23:93-6.

35. Ouattara B, Kra O, Yao H, et al. [Characteristics of chronic renal failure in black adult patients hospitalized in the Internal Medicine department of Treichville University Hospital]. Nephrol Ther 2011;7:531-4

36. Lengani A, Coulibaly G, Laville M, et al. [Epidemiology of severe chronic renal insufficiency in Burkina Faso]. Sante 1997;7:379-83.

37. Afifi AM, Mady GE, Ahmad AA, et al. Pattern of renal diseases among elderly Egyptians patients with acute or chronic renal diseases in Ain Shams University and Nasser Institute Hospitals, Cairo, Egypt. J Egypt Soc Parasitol 2005;35:911-24.

38. Diouf $B, K a$ EF, Niang A, et al. [Etiologies of chronic renal insufficiency in a adult internal medicine service in Dakar]. Dakar Med 2000;45:62-5.

39. Niang A, Dial C, Ka EF, et al. [Nephrotic syndrom with focal and segmental glomerulosclerosis in Dakar: epidemiological and clinicopathological characteristics (about 134 cases)]. Dakar Med 2008;53:45-51.

40. Sabi KA, Gnionsahe DA, Amedegnato D. [Chronic kidney failure in Togo: clinical, laboratory, and etiological aspects]. Med Trop 2011;71:74-6.

41. Ulasi II, ljoma CK. The enormity of chronic kidney disease in Nigeria: the situation in a teaching hospital in South-East Nigeria. $J$ Trop Med 2010;2010:1-6.

42. Abderrahim E, Zouaghi K, Hedri H, et al. Renal replacement therapy for diabetic end-stage renal disease. Experience of a Tunisian hospital centre. Diabetes Metab 2001;27:584-90.

43. Abdou N, Boucar D, El Hadj Fary KA, et al. Histopathological profiles of nephropathies in senegal. Saudi J Kidney Dis Transpl 2003;14:212-4

44. Afifi A, El Setouhy M, El Sharkawy M, et al. Diabetic nephropathy as a cause of end-stage renal disease in Egypt: a six-year study. East Mediterr Health J 2004;10:620-6.

45. Afifi A, Karim MA. Renal replacement therapy in Egypt: first annual report of the Egyptian Society of Nephrology, 1996. East Mediterr Health J 1999;5:1023-9.

46. Agaba El, Wigwe CM, Agaba PA, et al. Performance of the Cockcroft-Gault and MDRD equations in adult Nigerians with chronic kidney disease. Int Urol Nephrol 2009;41:635-42.

47. Alashek WA, McIntyre CW, Taal MW. Epidemiology and aetiology of dialysis-treated end-stage kidney disease in Libya. BMC Nephrol 2012;13:33

48. Alasia DD, Emem-Chioma P, Wokoma FS. A single-center 7-year experience with end-stage renal disease care in Nigeria-a surrogate for the poor state of ESRD care in Nigeria and other sub-saharan african countries: advocacy for a global fund for ESRD care program in sub-saharan african countries. Int $J$ Nephrol 2012;2012:1-7

49. Alebiosu CO, Ayodele OO, Abbas A, et al. Chronic renal failure at the Olabisi Onabanjo University Teaching Hospital, Sagamu, Nigeria. Afr Health Sci 2006;6:132-8.

50. Amira CO, Braimoh RW, Bello BT. Pattern of intradialytic complications at the Lagos University Teaching Hospital. Afr J Med Med Sci 2012;41:411-6.

51. Arogundade FA, Sanusi AA, Hassan MO, et al. The pattern clinical characteristics and outcome of ESRD in lle-lfe, Nigeria: is there a change in trend?Afr health sci 2011:11:594-601.

52. Counil E, Cherni N, Kharrat M, et al. Trends of incident dialysis patients in Tunisia between 1992 and 2001. Am J Kidney Dis 2008:51:463-70.
53. Chijioke A, Makusidi AM, Kolo PM. Electrocardiographic abnormalities among dialysis naïve chronic kidney disease patients in Ilorin Nigeria. Ann Afr Med 2012;11:21-6.

54. Madala ND, Thusi GP, Assounga AG, et al. Characteristics of South African patients presenting with kidney disease in rural KwaZuluNatal: a cross sectional study. BMC Nephrol 2014;15:61.

55. Okpechi IG, Ayodele OE, Rayner BL, et al. Kidney disease in elderly South Africans. Clin Nephrol 2013;79:269-76.

56. Laleye A, Awede B, Agboton B, et al. Autosomal dominant polycystic kidney disease in University Clinic of Nephrology and Haemodialysis of Cotonou: clinical and genetical findings. Genet Couns 2012:23:435-45.

57. Okunola Y, Ayodele O, Akinwusi P, et al. Haemodialysis practice in a resource-limited setting in the tropics. Ghana Med J 2013;47:4-9.

58. Bello BT, Raji YR, Sanusi I, et al. Challenges of providing maintenance hemodialysis in a resource poor country: Experience from a single teaching hospital in Lagos, Southwest Nigeria. Hemodial Int 2013;17:427-33.

59. El Minshawy O. End-stage renal disease in the El-Minia Governorate, upper Egypt: an epidemiological study. Saudi J Kidney Dis Transp/ 2011;22:1048-54.

60. Okpechi IG, Rayner BL, Swanepoel CR. Nephrotic syndrome in adult black South Africans: HIV-associated nephropathy as the main culprit. J Natl Med Assoc 2010;102:1193-7.

61. Madala ND, Nkwanyana N, Dubula T, et al. Predictive performance of eGFR equations in South Africans of African and Indian ancestry compared with $\square \square \mathrm{mTc}$-DTPA imaging. Int Urol Nephrol 2012;44:847-55.

62. El Farouki MR, Bahadi A, Hamzi MA, et al. [Profile of chronic renal failure in diabetes at initiation of hemodialysis in the nephrology and dialysis service of the military hospital in Rabat, Morocco]. Pan Afr Med J 2013;15:124.

63. Okpechi I, Swanepoel C, Duffield M, et al. Patterns of rena disease in Cape Town South Africa: a 10-year review of a single-centre renal biopsy database. Nephrol Dial Transplant 2011;26:1853-61.

64. Niang A, Cisse MM, Mahmoud SM, et al. Pilot experience in senegal with peritoneal dialysis for end-stage renal disease. Perit Dial Int 2014;34:539-43.

65. Buargub MA. 5-year mortality in hemodialysis patients: a single center study in Tripoli. Saudi J Kidney Dis Transp/ 2008;19:268-73.

66. Chijioke A, Aderibigbe A, Olarenwaju TO, et al. Prevalence and pattern of cystic kidney diseases in llorin, Nigeria. Saudi J Kidney Dis Transpl 2010;21:1172-8.

67. Elsharif ME, Elsharif EG. Causes of end-stage renal disease in Sudan: a single-center experience. Saudi J Kidney Dis Transpl 2011;22:373-6.

68. Elkhatib M, Elnahed MS, Fadda S, et al. The change in the spectrum of glomerulonephritis in Egypt over the past decade. Saudi J Kidney Dis Transpl 2012;23:1065-7.

69. Ibrahim S, Fayed A, Fadda S, et al. A five-year analysis of the incidence of glomerulonephritis at Cairo University Hospital-Egypt. Saudi J Kidney Dis Transpl 2012;23:866-70.

70. Ayach G, El-Filali H, Saidi S, et al. Histopathological study of pure primary nephrotic syndrome in adolescents and young Moroccan adults. Arab J Nephrol Transplant 2011;4:137-40.

71. Ramilitiana $B$, Ranivoharisoa EM, Dodo $M$, et al. [A retrospective study on the incidence of chronic renal failure in the Department of Internal Medicine and Nephrology at University Hospital of Antananarivo (the capital city of Madagascar)]. Pan Afr Med J 2016;23:141.

72. Zajjari Y, Benyahia M, Ibrahim DM, et al. La néphropathie non diabétique chez les patients diabétiques de type 2 à l'hôpital militaire Mohammed V de Rabat (Maroc). EMHJ 2012;18.

73. Fatiu A, Abubakr S, Muzamil H, et al. Undiagnosed hypertension and proteinuria in a market population in lle-lfe, Nigeria. Arab $J$ Nephrol Transplant 2011:4:141-6.

74. Traore M, Traore HA, Kardorff R, et al. The public health significance of urinary schistosomiasis as a cause of morbidity in two districts in Mali. Am J Trop Med Hyg 1998;59:407-13.

75. Sumaili EK, Nseka NM, Lepira FB, et al. Screening for proteinuria and chronic kidney disease risk factors in Kinshasa: a World Kidney Day 2007 study. Nephron Clin Pract 2008;110:c220-8.

76. Egbi OG, Okafor UH, Miebodei KE, et al. Prevalence and correlates of chronic kidney disease among civil servants in Bayelsa state, Nigeria. Niger J Clin Pract 2014;17:602-7.

77. Ayodele OE, Okunola OO, Afolabi MO, et al. Prevalence of hypertension, diabetes and chronic kidney disease in participants of the 2009 World Kidney Day screening exercise in Southwest Nigeria. HKJN 2011;13:55-63. 
78. Abu-Aisha H, Elhassan A, Khamis A, et al. Chronic kidney disease in police forces households in Khartoum, Sudan: pilot report. Arab J Nephrol Transplant 2009;2:21-6.

79. Cailhol J, Nkurunziza B, Izzedine $\mathrm{H}$, et al. Prevalence of chronic kidney disease among people living with HIV/AIDS in Burundi: a cross-sectional study. BMC Nephrol 2011;12:40.

80. Wools-Kaloustian K, Gupta SK, Muloma E, et al. Renal disease in an antiretroviral-naive HIV-infected outpatient population in Western Kenya. Nephrol Dial Transplant 2007;22:2208-12.

81. Emem CP, Arogundade F, Sanusi A, et al. Renal disease in HIVseropositive patients in Nigeria: an assessment of prevalence, clinical features and risk factors. Nephrol Dial Transplant 2008;23:741-6.

82. Wyatt CM, Shi Q, Novak JE, et al. Prevalence of kidney disease in HIV-infected and uninfected Rwandan women. PLoS One 2011;6:e18352.

83. FolefackKaze F, Kengne AP, Pefura Yone EW, et al. Renal function, urinalysis abnormalities and correlates among HIV-infected Cameroonians naive to antiretroviral therapy. Saudi J Kidney Dis Transp/ 2013;24:1291-7.

84. Struik GM, den Exter RA, Munthali C, et al. The prevalence of renal impairment among adults with early HIV disease in Blantyre, Malawi. Int J STD AIDS 2011;22:457-62.

85. Msango L, Downs JA, Kalluvya SE, et al. Renal dysfunction among HIV-infected patients starting antiretroviral therapy. AIDS 2011;25:1421-5.

86. Janmohamed MN, Kalluvya SE, Mueller A, et al. Prevalence of chronic kidney disease in diabetic adult out-patients in Tanzania. BMC Nephrol 2013;14:183.

87. Wanjohi FW, Otieno FC, Ogola EN, et al. Nephropathy in patients with recently diagnosed type 2 diabetes mellitus in black Africans. East Afr Med J 2002;79:399-404.

88. Choukem SP, Dzudie A, Dehayem M, et al. Comparison of different blood pressure indices for the prediction of prevalent diabetic nephropathy in a sub-Saharan African population with type 2 diabetes. Pan Afr Med J 2012;11:67.

89. Plange-Rhule J, Phillips R, Acheampong JW, et al. Hypertension and renal failure in Kumasi, Ghana. J Hum Hypertens 1999;13:37-40

90. Kalyesubula R, Nankabirwa JI, Ssinabulya I, et al. Kidney disease in Uganda: a community based study. BMC Nephrol 2017;18:116.

91. Kaze FF, Halle MP, Mopa HT, et al. Prevalence and risk factors of chronic kidney disease in urban adult Cameroonians according to three common estimators of the glomerular filtration rate: a crosssectional study. BMC Nephrol 2015;16:96.

92. Lunyera J, Stanifer JW, Ingabire P, et al. Prevalence and correlates of proteinuria in Kampala, Uganda: a cross-sectional pilot study. BMC Res Notes 2016:9:97.

93. Wachukwu CM, Emem-Chioma PC, Wokoma FS, et al. Prevalence of risk factors for chronic kidney disease among adults in a university community in southern Nigeria. Pan Afr Med $\mathrm{J}$ 2015;21:120.

94. Odongo $\mathrm{P}$, Wanyama $\mathrm{R}$, Obol JH, et al. Impaired renal function and associated risk factors in newly diagnosed HIV-infected adults in Gulu Hospital, Northern Uganda. BMC Nephrol 2015;16:43.

95. Feteh VF, Choukem SP, Kengne AP, et al. Anemia in type 2 diabetic patients and correlation with kidney function in a tertiary care subSaharan African hospital: a cross-sectional study. BMC Nephrol 2016;17:29.

96. Pillay S, Aldous C, Mahomed F. A deadly combination - HIV and diabetes mellitus: Where are we now? S Afr Med J 2016;106:378

97. Seck SM, Doupa D, Guéye L, et al. Chronic kidney disease epidemiology in northern Senegal: a cross-sectional study. Iran J Kidney Dis 2014;8:286-91.

98. Sumaili EK, Krzesinski JM, Zinga CV, et al. Prevalence of chronic kidney disease in Kinshasa: results of a pilot study from the Democratic Republic of Congo. Nephrol Dial Transplant 2009:24:117-22.

99. Longo AL, Lepira FB, Sumaili EK, et al. Prevalence of low estimated glomerular filtration rate, proteinuria, and associated risk factors among HIV-infected black patients using Cockroft-Gault and modification of diet in renal disease study equations. J Acquir Immune Defic Syndr 2012;59:59-64.

100. Fana GT, Ndhlovu CE. Renal dysfunction among anti-retroviral therapy naïve HIV infected patients in Zimbabwe. Cent Afr J Med 2011:57:1-5.

101. Han TM, Naicker S, Ramdial PK, et al. A cross-sectional study of HIV-seropositive patients with varying degrees of proteinuria in South Africa. Kidney Int 2006;69:2243-50.

102. Balogun WO, Abbiyesuku FM. Excess renal insufficiency among type 2 diabetic patients with dip-stick positive proteinuria in a tertiary hospital. Afr J Med Med Sci 2011;40:399-403.
103. Mafundikwa A, Ndhlovu CE, Gomo Z. The prevalence of diabetic nephropathy in adult patients with insulin dependent diabetes mellitus attending Parirenyatwa Diabetic Clinic, Harare. Cent Afr J Med 2007:53:1-6.

104. Hamdouk M, Abdelraheem M, Taha A, et al. The association between prolonged occupational exposure to paraphenylenediamine (hair-dye) and renal impairment. Arab $J$ Nephrol Transplant 2011;4:21-5.

105. Oluyombo R, Ayodele OE, Akinwusi PO, et al. A community study of the prevalence, risk factors and pattern of chronic kidney disease in Osun State, South West Nigeria. West Afr J Med 2013;32:85-92.

106. Prevalence of Chronic Kidney Disease and Associated Risk Factors: First Results from a Population Based Screening Program in Morocco(MAREMAR) [ASN abstract 353]. J Am Soc Nephrol 2012.

107. Masimango MI, Sumaili EK, Jadoul M, et al. Prevalence of microalbuminuria and diagnostic value of dipstick proteinuria in outpatients from HIV clinics in Bukavu, the Democratic Republic of Congo. BMC Nephrol 2014;15:146.

108. Fabian J, Naicker S, Venter WD, et al. Urinary screening abnormalities in antiretroviral-naive HIV-infected outpatients and implications for management-a single-center study in South Africa. Ethn Dis 2009;19(1 Suppl 1):S1-80.

109. Sarfo FS, Keegan R, Appiah L, et al. High prevalence of renal dysfunction and association with risk of death amongst HIVinfected Ghanaians. J Infect 2013;67:43-50.

110. Jao J, Palmer D, Leus I, et al. Prevalence and predictors of proteinuria in HIV-infected and uninfected pregnant women in Cameroon. Nephrol Dial Transplant 2011;26:3051-3.

111. Makulo R, Nseka MN, Jadoul M, et al. Albuminurie pathologique lors du dépistage du diabète en milieu semi-rural (cité de Kisantu en RD Congo). Nephrol Ther 2010;6:513-9.

112. Kaze FF, Kengne AP, Magatsing CT, et al. Prevalence and Determinants of Chronic Kidney Disease Among Hypertensive Cameroonians According to Three Common Estimators of the Glomerular Filtration Rate. J Clin Hypertens 2016;18:408-14.

113. Ayokunle DS, Olusegun OT, Ademola A, et al. Prevalence of chronic kidney disease in newly diagnosed patients with Human immunodeficiency virus in Ilorin, Nigeria. J Bras Nefrol 2015;37:177-84.

114. Chadwick DR, Sarfo FS, Kirk ES, et al. Tenofovir is associated with increased tubular proteinuria and asymptomatic renal tubular dysfunction in Ghana. BMC Nephrol 2015;16:195.

115. Glaser N, Phiri S, Bruckner T, et al. The prevalence of renal impairment in individuals seeking HIV testing in Urban Malawi. BMC Nephrol 2016;17:186.

116. Pruijm MT, Madeleine G, Riesen WF, et al. Prevalence of microalbuminuria in the general population of Seychelles and strong association with diabetes and hypertension independent of renal markers. J Hypertens 2008;26:871-7.

117. Gouda Z, Mashaal G, Bello AK, et al. Egypt information, prevention, and treatment of chronic kidney disease (EGIPT-CKD) programme: prevalence and risk factors for microalbuminuria among the relatives of patients with CKD in Egypt. Saudi J Kidney Dis Transpl 2011;22:1055.

118. Attolou V, Bigot A, Ayivi B, et al. [Renal complications associated with human acquired immunodeficiency virus infection in a population of hospital patients at the Hospital and University National Center in Cotonou]. Sante 1998;8:283-6.

119. Bouzid C, Smida H, Kacem A, et al. [Renal failure in Tunisian patients with type 2 diabetes: frequency and related factors]. Tunis Med 2011;89:10-15.

120. Keeton GR, Smit R, Bryer A. Renal outcome of type 2 diabetes in South Africa-a 12-year follow-up study. S Afr Med J 2004;94:771-5.

121. Bouaziz A, Zidi I, Zidi N, et al. Nephropathy following type 2 diabetes mellitus in Tunisian population. West Indian Med $J$ 2012;61:881-9.

122. Katchunga P, Hermans MP, Manwa B, et al. [Hypertension, insulin resistance and chronic kidney disease in type 2 diabetes patients from South Kivu, DR Congo]. Nephrol Ther 2010;6:520-5.

123. Djrolo F, Attolou VG, Avode DG, et al. [Diabetic nephropathy: an epidemiological study based on proteinuria in a population of black African diabetics in Cotonou, Benin]. Sante 2001:11:105-9.

124. Lutale JJ, Thordarson H, Abbas ZG, et al. Microalbuminuria among type 1 and type 2 diabetic patients of African origin in Dar Es Salaam, Tanzania. BMC Nephrol 2007:8:2.

125. Gill G, Gebrekidan A, English P, et al. Diabetic complications and glycaemic control in remote North Africa. QJM 2008;101:793-8.

126. Osafo C, Mate-Kole M, Affram K, et al. Prevalence of chronic kidney disease in hypertensive patients in Ghana. Ren Fail 2011:33:388-92. 
127. Lengani A, Samadoulougou A, Cissé M. [Characteristics of renal disease in hypertensive morbidities in adults in Burkina Faso]. Arch Mal Coeur Vaiss 2000;93:1053-7.

128. Rayner B, Becker $P$. The prevalence of microalbuminuria and ECG left ventricular hypertrophy in hypertensive patients in private practices in South Africa. Cardiovasc J S Afr 2006;17:245-9.

129. EL-Safty IA, Gadallah M, Shouman AE, et al. Subclinical nephrotoxicity caused by smoking and occupational silica exposure among Egyptian industrial workers. Arch Med Res 2003:34:415-21.

130. Laurence EC, Volmink J, Esterhuizen TM, et al. Risk of cardiovascular disease among teachers in Cape Town: Findings of the South African PaCT pilot study. S Afr Med J 2016;106:996-1001.

131. Mogueo A, Echouffo-Tcheugui JB, Matsha TE, et al. Validation of two prediction models of undiagnosed chronic kidney disease in mixed-ancestry South Africans. BMC Nephrol 2015;16:94.

132. Stanifer JW, Egger JR, Turner EL, et al. Neighborhood clustering of non-communicable diseases: results from a community-based study in Northern Tanzania. BMC Public Health 2016;16:226.

133. Stanifer JW, Maro V, Egger J, et al. The epidemiology of chronic kidney disease in Northern Tanzania: a population-based survey. PLoS One 2015;10:e0124506.

134. Stanifer JW, Turner EL, Egger JR, et al. Knowledge, Attitudes, and Practices Associated with Chronic Kidney Disease in Northern Tanzania: A Community-Based Study. PLoS One 2016;11:e0156336.

135. Anyabolu EN, Chukwuonye II, Arodiwe E, et al. Prevalence and predictors of chronic kidney disease in newly diagnosed human immunodeficiency virus patients in Owerri, Nigeria. Indian J Nephrol 2016;26:10-15.

136. Okafor UH, Unuigbe El, Chukwuonye E. Prevalence and clinical and laboratory characteristics of kidney disease in anti-retroviral-naive human immunodeficiency virus-infected patients in South-South Nigeria. Saudi J Kidney Dis Transp/ 2016;27:129-34.

137. Wensink GE, Schoffelen AF, Tempelman HA, et al. Albuminuria Is Associated with Traditional Cardiovascular Risk Factors and Viral Load in HIV-Infected Patients in Rural South Africa. PLoS One 2015;10:e0136529.

138. Eghan BA, Frempong MT, Adjei-Poku M. Prevalence and predictors of microalbuminuria in patients with diabetes mellitus: a cross-sectional observational study in Kumasi, Ghana. Ethn Dis 2007; $17: 726-30$.

139. Aryee C, Owiredu WK, Osei-Yeboah J, et al. An Analysis of Anthropometric Indicators and Modifiable Lifestyle Parameters Associated with Hypertensive Nephropathy. Int J Hypertens 2016;2016:1-14

140. Nabbaale J, Kibirige D, Ssekasanvu E, et al. Microalbuminuria and left ventricular hypertrophy among newly diagnosed black African hypertensive patients: a cross sectional study from a tertiary hospital in Uganda. BMC Res Notes 2015;8:198.

141. Addo J, Smeeth L, Leon DA. Hypertensive target organ damage in Ghanaian civil servants with hypertension. PLoS One 2009;4:e6672.

142. Owiredu WK, Quaye L, Amidu N, et al. Renal insufficiency in Ghanaian HIV infected patients: need for dose adjustment. Af Health Sci 2013;13:101-11

143. Stöhr W, Reid A, Walker AS, et al. Glomerular dysfunction and associated risk factors over 4-5 years following antiretroviral therapy initiation in Africa. Antivir Ther 2011;16:1011-20.

144. Stöhr W, Walker AS, Munderi P, et al. Estimating glomerular filtration rate in HIV-infected adults in Africa: comparison of Cockcroft-Gault and Modification of Diet in Renal Disease formulae. Antivir Ther 2008;13:761-70.

145. Reid A, Stöhr W, Walker AS, et al. Severe renal dysfunction and risk factors associated with renal impairment in HIV-infected adults in Africa initiating antiretroviral therapy. Clin Infect Dis 2008:46:1271-81.

146. Ekat $\mathrm{MH}$, Courpotin $\mathrm{C}$, Diafouka $\mathrm{M}$, et al. [Prevalence and factors associated with renal disease among patients with newly diagnoses of HIV in Brazzaville, Republic of Congo]. Med Sante Trop 2013:23:176-80.

147. Peters PJ, Moore DM, Mermin J, et al. Antiretroviral therapy improves renal function among HIV-infected Ugandans. Kidney Int 2008;74:925-9.

148. Peck R, Baisley K, Kavishe B, et al. Decreased renal function and associated factors in cities, towns and rural areas of Tanzania: a community-based population survey. Trop Med Int Health 2016;21:393-404.

149. Nsagha DS, Pokam BT, Assob JC, et al. HAART, DOTS and renal disease of patients co-infected with HIV/AIDS and TB in the South West Region of Cameroon. BMC Public Health 2015;15:1040.
150. Mekuria Y, Yilma D, Mekonnen Z, et al. Renal Function Impairment and Associated Factors among HAART Naïve and Experienced Adult HIV Positive Individuals in Southwest Ethiopia: A Comparative Cross Sectional Study. PLoS One 2016;11:e0161180.

151. Adebamowo SN, Adeyemo AA, Tekola-Ayele F, et al. Impact of Type 2 Diabetes on Impaired Kidney Function in Sub-Saharan African Populations. Front Endocrinol 2016;7:50.

152. Fiseha T, Kassim M, Yemane T. Chronic kidney disease and underdiagnosis of renal insufficiency among diabetic patients attending a hospital in Southern Ethiopia. BMC Nephrol 2014;15:198.

153. Odenigbo $\mathrm{C}$, Oguejiofor $\mathrm{O}$, Onwubuya $\mathrm{E}$, et al. The prevalence of chronic kidney disease in apparently healthy retired subjects in asaba, Nigeria. Ann Med Health Sci Res 2014;4(Suppl 2):S128-32.

154. Lucas GM, Clarke W, Kagaayi J, et al. Decreased Kidney Function in a Community-based Cohort of HIV-Infected and HIV-Negative Individuals in Rakai, Uganda. J Acquir Immune Defic Syndr 2010:55:491-4.

155. Booysen HL, Woodiwiss AJ, Raymond A, et al. Chronic kidney disease epidemiology collaboration-derived glomerular filtration rate performs better at detecting preclinical end-organ changes than alternative equations in black Africans. $J$ Hypertens 2016;34:1178-85

156. Seape T, Gounden V, van Deventer HE, et al. Cystatin C- and creatinine-based equations in the assessment of renal function in HIV-positive patients prior to commencing Highly Active Antiretroviral Therapy. Ann Clin Biochem 2016;53:58-66.

157. Zachor H, Machekano R, Estrella MM, et al. Incidence of stage 3 chronic kidney disease and progression on tenofovir-based regimens. AIDS 2016;30:1221-8.

158. Adedeji TA, Adedeji NO, Adebisi SA, et al. Prevalence and Pattern of Chronic Kidney Disease in Antiretroviral-Naïve Patients with HIV/ AIDS. J Int Assoc Provid AIDS Care 2015;14:434-40.

159. Matsha TE, Soita DJ, Hassan SM, et al. Deterioration, improvement of kidney function over time and determinants in the Cape Town Bellville South cohort. Nephrology 2014;19:638-47.

160. Jao J, Lo W, Toro PL, et al. Factors associated with decreased kidney function in HIV-infected adults enrolled in the MTCT-Plus Initiative in sub-Saharan Africa. J Acquir Immune Defic Syndr 2011;57:40-5

161. Gupta SK, Ong'or WO, Shen C, et al. Reduced renal function is associated with progression to AIDS but not with overall mortality in HIV-infected Kenyan adults not initially requiring combination antiretroviral therapy. J Int AIDS Soc 2011;14:31.

162. Myer L, Kamkuemah M, Kaplan R, et al. Low prevalence of renal dysfunction in HIV-infected pregnant women: implications for guidelines for the prevention of mother-to-child transmission of HIV. Trop Med Int Health 2013;18:1400-5.

163. Mulenga LB, Kruse G, Lakhi S, et al. Baseline renal insufficiency and risk of death among HIV-infected adults on antiretroviral therapy in Lusaka, Zambia. AIDS 2008;22:1821-7.

164. Ajayi S, Mamven M, Ojji D. eGFR and chronic kidney disease stages among newly diagnosed asymptomatic hypertensives and diabetics seen in a tertiary health center in Nigeria. Ethn Dis 2014:24:220-5.

165. Nwankwo EA, Nwankwo B, Mubi B. Prevalence of impaired kidney function in hospitalized hypertensive patients in Maiduguri, Nigeria. Intern J Intern Med 2006;6.

166. Edwards JK, Bygrave H, Van den Bergh R, et al. HIV with noncommunicable diseases in primary care in Kibera, Nairobi, Kenya: characteristics and outcomes 2010-2013. Trans $R$ Soc Trop Med Hyg 2015;109:440-6.

167. Kamkuemah M, Kaplan R, Bekker LG, et al. Renal impairment in HIV-infected patients initiating tenofovir-containing antiretroviral therapy regimens in a Primary Healthcare Setting in South Africa. Trop Med Int Health 2015;20:518-26.

168. Levey AS, Coresh J, Balk E, et al. National Kidney Foundation practice guidelines for chronic kidney disease: evaluation, classification, and stratification. Ann Intern Med 2003:139:137-47.

169. Abdelsatir S, Al-Sofi A, Elamin S, et al. The potential role of nursing students in the implementation of community-based hypertension screening programs in Sudan. Arab J Nephrol Transplant 2013;6:51-4.

170. Agaba El, Agaba PA, Sirisena ND, et al. Renal disease in the acquired immunodeficiency syndrome in north central Nigeria. Niger $J$ Med 2003;12:120-5.

171. Coresh J, Astor BC, McQuillan G, et al. Calibration and random variation of the serum creatinine assay as critical elements of using equations to estimate glomerular filtration rate. Am J Kidney Dis 2002;39:920-9.

172. Liu WS, Chung YT, Yang CY, et al. Serum creatinine determined by Jaffe, enzymatic method, and isotope dilution-liquid 
chromatography-mass spectrometry in patients under hemodialysis. J Clin Lab Anal 2012;26:206-14.

173. Drion I, Cobbaert C, Groenier KH, et al. Clinical evaluation of analytical variations in serum creatinine measurements: why laboratories should abandon Jaffe techniques. BMC Nephrol 2012;13:133.

174. Bachmann LM, Nilsson G, Bruns DE, et al. State of the art for measurement of urine albumin: comparison of routine measurement procedures to isotope dilution tandem mass spectrometry. Clin Chem 2014;60:471-80.

175. Levey AS, Stevens LA. Estimating GFR using the CKD Epidemiology Collaboration (CKD-EPI) creatinine equation: more accurate GFR estimates, lower CKD prevalence estimates, and better risk predictions. Am J Kidney Dis 2010;55:622-7.

176. Cobo G, Hecking M, Port FK, et al. Sex and gender differences in chronic kidney disease: progression to end-stage renal disease and haemodialysis. Clin Sci 2016;130:1147-63.

177. Nitsch D, Grams M, Sang Y, et al. Associations of estimated glomerular filtration rate and albuminuria with mortality and renal failure by sex: a meta-analysis. BMJ 2013;346:f324.

178. Poggio ED, Rule AD. A critical evaluation of chronic kidney diseaseshould isolated reduced estimated glomerular filtration rate be considered a 'disease'? Nephrol Dial Transplant 2009;24:698-700.

179. Hill NR, Fatoba ST, Oke JL, et al. Global Prevalence of Chronic Kidney Disease - A Systematic Review and Meta-Analysis. PLoS One 2016;11:e0158765.

180. Saran R, Li Y, Robinson B, et al. US Renal Data System 2014 Annual Data Report: Epidemiology of Kidney Disease in the United States. Am J Kidney Dis 2015;66(1 Suppl 1):S1-305.

181. Brück K, Stel VS, Gambaro G, et al. CKD Prevalence Varies across the European General Population. J Am Soc Nephrol 2016;27:2135-47.

182. Ingsathit $A$, Thakkinstian A, Chaiprasert A, et al. Prevalence and risk factors of chronic kidney disease in the Thai adult population: Thai SEEK study. Nephrol Dial Transplant 2010;25:1567-75.

183. Singh AK, Farag YM, Mittal BV, et al. Epidemiology and risk factors of chronic kidney disease in India - results from the SEEK (Screening and Early Evaluation of Kidney Disease) study. BMC Nephrol 2013;14:114.

184. Imai E, Horio M, Watanabe T, et al. Prevalence of chronic kidney disease in the Japanese general population. Clin Exp Nephrol 2009;13:621-30.

185. Hwang SJ, Tsai JC, Chen HC. Epidemiology, impact and preventive care of chronic kidney disease in Taiwan. Nephrology 2010;15(Suppl 2):3-9.

186. Lin B, Shao L, Luo Q, et al. Prevalence of chronic kidney disease and its association with metabolic diseases: a cross-sectional survey in Zhejiang province, Eastern China. BMC Nephrol 2014;15:36

187. Tomonaga Y, Risch L, Szucs TD, et al. The prevalence of chronic kidney disease in a primary care setting: a Swiss cross-sectional study. PLoS One 2013;8:e67848.

188. Jha V, Garcia-Garcia G, Iseki K, et al. Chronic kidney disease: global dimension and perspectives. Lancet 2013;382:260-72.

189. Barsoum RS. Chronic kidney disease in the developing world. $N$ Engl J Med 2006;354:997-9.

190. UNAIDS. HIV and AIDS estimates. UNAIDS, 2015. http://www. unaids.org/en/regionscountries/countries/senegal (accessed $15 \mathrm{Jul}$ 2015).
191. UNAIDS. HIV and AIDS estimates. UNAIDS, 2015. http://www. unaids.org/en/regionscountries/countries/swaziland (accessed 1 Aug 2015).

192. Matic S, Lazarus JV, Donoghoe MC. HIVIAIDS in Europe: moving from death sentence to chronic disease management. World Health Organization, 2006

193. Estrella M, Fine DM, Gallant JE, et al. HIV type 1 RNA level as a clinical indicator of renal pathology in HIV-infected patients. Clin Infect Dis 2006;43:377-80.

194. Déti EK, Thiébaut R, Bonnet F, et al. Prevalence and factors associated with renal impairment in HIV-infected patients, ANRS C03 Aquitaine Cohort, France. HIV Med 2010;11:308-17.

195. Fernando SK, Finkelstein FO, Moore BA, et al. Prevalence of chronic kidney disease in an urban HIV infected population. Am J Med Sci 2008;335:89-94.

196. Cao Y, Gong M, Han Y, et al. Prevalence and risk factors for chronic kidney disease among HIV-infected antiretroviral therapy-naïve patients in mainland China: a multicenter cross-sectional study. Nephrology 2013;18:307-12.

197. Rustarazo SB, Fuente SR, de Miguel SC, et al. Prevalence and spectrum of chronic kidney disease in HIV-positive patients: GRP031 Table 1. Eur J Hosp Pharm 2012;19:96.3-7.

198. Menezes AM, Torelly J, Real L, et al. Prevalence and risk factors associated to chronic kidney disease in HIV-infected patients on HAART and undetectable viral load in Brazil. PLoS One 2011;6:e26042.

199. Sicotte M, Langlois ÉV, Aho J, et al. Association between nutritional status and the immune response in HIV + patients under HAART: protocol for a systematic review. Syst Rev 2014;3:9.

200. Taylor BS, Sobieszczyk ME, McCutchan FE, et al. The challenge of HIV-1 subtype diversity. N Engl J Med 2008;358:1590-602.

201. Wools-Kaloustian KK, Gupta SK. Will there be an epidemic of HIVrelated chronic kidney disease in sub-Saharan Africa? Too soon to tell. Kidney Int 2008;74:845-7.

202. Pokroy-Shapira E, Gelernter I, Molad Y. Evolution of chronic kidney disease in patients with systemic lupus erythematosus over a long-period follow-up: a single-center inception cohort study. Clin Rheumatol 2014;33:649-57.

203. Mak A, Mok CC, Chu WP, et al. Renal damage in systemic lupus erythematosus: a comparative analysis of different age groups. Lupus 2007;16:28-34.

204. Rabbani MA, Tahir MH, Siddiqui BK, et al. Renal involvement in systemic lupus erythematosus in Pakistan. J Pak Med Assoc 2005;55:328-32.

205. Chiu HY, Huang HL, Li CH, et al. Increased Risk of Chronic Kidney Disease in Rheumatoid Arthritis Associated with Cardiovascular Complications - A National Population-Based Cohort Study. PLoS One 2015;10:e0136508.

206. Barsoum RS. End-stage renal disease in North Africa. Kidney Int Suppl 2003;83:S111-4.

207. Naicker S. End-stage renal disease in Sub-Saharan Africa. Kidney Int Suppl 2013;3:161-3.

208. Naicker S. Challenges for nephrology practice in Sub-Saharan Africa. Nephrol Dial Transplant 2010;25:649-50.

209. Noubiap JJ, Naidoo J, Kengne AP. Diabetic nephropathy in Africa: A systematic review. World J Diabetes 2015;6:759-73.

210. Brook MO, Bottomley MJ, Mevada C, et al. Repeat testing is essential when estimating chronic kidney disease prevalence and associated cardiovascular risk. QJM 2012;105:247-55. 